\title{
The resolution sensitivity of the Asian summer monsoon and its inter-model comparison between MRI-AGCM and MetUM
}

Article

Accepted Version

Ogata, T., Johnson, S. J., Schiemann, R., Demory, M.-E., Mizuta, R., Yoshida, K. and Arakawa, O. (2017) The resolution sensitivity of the Asian summer monsoon and its inter-model comparison between MRI-AGCM and MetUM. Climate Dynamics, 49 (9-10). pp. 3345-3361. ISSN 0930-7575 doi: https://doi.org/10.1007/s00382-016-3517-5 Available at https://centaur.reading.ac.uk/68644/

It is advisable to refer to the publisher's version if you intend to cite from the work. See Guidance on citing.

To link to this article DOI: http://dx.doi.org/10.1007/s00382-016-3517-5

Publisher: Springer

All outputs in CentAUR are protected by Intellectual Property Rights law, including copyright law. Copyright and IPR is retained by the creators or other copyright holders. Terms and conditions for use of this material are defined in the End User Agreement. 


\section{www.reading.ac.uk/centaur}

\section{CentAUR}

Central Archive at the University of Reading

Reading's research outputs online 

its Inter-Model Comparison between MRI-AGCM and MetUM

9 Stephanie J. Johnson², Reinhard Schiemann², Marie-Estelle Demory ${ }^{2}$,

$11{ }^{1}$ Faculty of Life and Environmental Sciences, University of Tsukuba, Japan

$12{ }^{2}$ National Centre for Atmospheric Science, Department of Meteorology,

13 University of Reading, UK

$14{ }^{3}$ Meteorological Research Institute, Tsukuba, Japan 
Abstract

In this study, we compare the resolution sensitivity of the Asian Summer Monsoon (ASM) in two Atmospheric General Circulation Models (AGCMs): the

23 MRI-AGCM and the MetUM. We analyze the MetUM at three different resolutions,

24 N96 (approximately 200-km mesh on the equator), N216 (90-km mesh) and N512 25 (40-km mesh), and the MRI-AGCM at TL95 (approximately 180-km mesh on the 26 equator), TL319 (60-km mesh), and TL959 (20-km mesh). The MRI-AGCM and the

27 MetUM both show decreasing precipitation over the western Pacific with increasing 28 resolution, but their precipitation responses differ over the Indian Ocean. In 29 MRI-AGCM, a large precipitation increase appears off the equator $\left(5-20^{\circ} \mathrm{N}\right)$. In MetUM, 30 this off-equatorial precipitation increase is less significant and precipitation decreases 31 over the equator. Moisture budget analysis demonstrates that a changing in moisture 32 flux convergence at higher resolution is related to the precipitation response.

33 Orographic effects, intra-seasonal variability and the representation of the meridional 34 thermal gradient are explored as possible causes of the resolution sensitivity. Both 35 high-resolution AGCMs (TL959 and N512) can represent steep topography, which 36 anchors the rainfall pattern over south Asia and the Maritime Continent. In MRI-AGCM, 37 representation of low pressure systems in TL959 also contributes to the rainfall pattern.

38 Furthermore, the seasonal evolution of the meridional thermal gradient appears to be 39 more accurate at higher resolution, particularly in the MRI-AGCM. These findings 40 emphasize that the impact of resolution is only robust across the two AGCMs for some 41 features of the ASM, and highlights the importance of multi-model studies of GCM 
42 resolution sensitivity.

43

44 


\section{Introduction}

The Asian Summer Monsoon (ASM) is an important component of the global

47 monsoon. Its multi-scale variability, ranging from sub-seasonal to inter-decadal time

48 scales, impacts society through natural disasters and changes in water resources (e.g.

49 Chang et al. 2000, Lau and Kim 2012, He and Zhou 2015, Joseph et al. 2015, Cho et al.

50 2015). Recent advances in climate simulation have improved the fidelity of the ASM,

51 but large biases remain. Sperber et al. (2013) and Ogata et al. (2014) reported that there

52 is little improvement in Coupled Model Intercomparison Project Phase 5 (CMIP5)

53 General Circulation Models (GCM) seasonal climatology compared to CMIP3 GCMs

54 and there are still substantial biases in the ASM simulations. At inter-annual timescales,

55 the ENSO-Indian monsoon relationship (defined by all-India rainfall and Nino-3.4) is

56 too strong in individual CMIP5 models, while the ENSO-East Asian monsoon

57 relationship is too weak in multi-model mean. CMIP3 and CMIP5 GCMs also

58 commonly exhibit a late monsoon onset (Sperber et al., 2013). At sub-seasonal

59 timescales, CMIP5 GCMs depict a large inter-model spread in the reproducibility of the

60 Boreal Summer Intra-Seasonal Oscillation (BSISO) of about 20-60 day period (e.g.

61 Yasunari 1980, Jiang et al. 2004, Ajayamohan et al. 2009).

62 The most significant differences between CMIP3 and CMIP5 GCMs are the

63 improvement of physics schemes and the increase in horizontal and vertical resolutions.

64 CMIP results include the model-produced SST bias, which makes the detection of

65 causes of model bias in the ASM simulation difficult. Therefore, an intercomparison of

66 atmospheric GCMs (AGCM) in an "AMIP-style" (Atmospheric Model Intercomparison 
67 Project) configuration, using observed SST and sea-ice boundary conditions, is often

68 more appropriate for diagnosing sources of bias or understanding the reason of response

69 changes in atmospheric models. In this paper, we focus on the effect of only increasing

70 horizontal resolution on the ASM simulation and perform an assessment with two 71 AGCMs.

72 Development in high-performance computing enables high-resolution AGCMs

73 that can resolve fine-scale orographic effect and synoptic-scale atmospheric variations.

74 Kitoh and Kusunoki (2008) investigated the ASM simulation in a 20-km resolution

75 AGCM and reported that increased resolution of steep orography improved the 76 precipitation climatology (Xie et al. 2006). Other resolution sensitivity studies have

77 shown that orographic precipitation over the Western Ghats and the Indochina peninsula

78 and the wind speed of Somali Jet are generally improved with increasing resolution

79 (Sperber et al. 1994, Jha et al. 2000, Kobayashi and Sugi 2004, Sabin et al. 2013).

80 However, resolution sensitivity of precipitation in other areas such as the western

81 equatorial Indian Ocean and Indian peninsula differs between studies (Sperber et al.

82 1994, Stephenson et al. 1998, Martin 1999, Sabin et al. 2013).

The 20-60 day BSISO, other intra-seasonal modes of 10-20 days (e.g.

84 Murakami 1976, Krishnamurti and Ardanuy 1980, Annamalai and Slingo 2001) and

85 synoptic 3-5 day Low Pressure Systems (LPS; e.g. Mak 1987, Goswami et al. 2003) all

86 interact on intra-seasonal time scales over the south Asia (Annamalai and Slingo 2001,

87 Goswami et al. 2003). These intra-seasonal variations and its multi-scale interactions

88 are considered as an important factor to the ASM reproducibility in GCMs (e.g. Liu et al. 
89 2009, Sperber et al. 2013, Sabeerali et al. 2013), and it is believed that high-resolution

90 GCMs better simulate such multi-scale interactions (e.g. Roberts et al, 2015; Vellinga et

91 al, 2016). Increasing horizontal resolution is also key to improving simulations of

92 tropical cyclones (TC; e.g. Oouchi et al. 2006, Murakami and Sugi 2010) and has some

93 common effects including improvement of TC distribution and intensity, decrease of

94 weak TC and increase of strong TC in the future climate (Murakami et al. 2012, Roberts

95 et al. 2015).

96 Each resolution sensitivity study uses slightly different techniques and analyses

97 different aspects of resolution sensitivity. Moreover, it is also well known that a large

98 inter-model spread in the reproducibility of the ASM exists, even in AMIP-style

99 simulations. For example, on the south Asian monsoon, Kitoh and Kusunoki (2008)

100 exhibited that major precipitation maximum locates around $10-20^{\circ} \mathrm{N}$ in MRI-AGCM at

101 both low and high resolutions. In contrast, Johnson et al. (2016) showed that major

102 precipitation maximum locates over the equator and precipitation around $10-20^{\circ} \mathrm{N}$ is

103 rather weak in MetUM at both low and high resolutions. In order to understand what

104 aspects of resolution sensitivity are common among GCMs, it is important to conduct a

105 coordinated resolution sensitivity study of multiple AGCMs using the same analysis

106 techniques.

107 In this study, based on Johnson et al. (2016), we compare the resolution 108 sensitivity of the ASM in two state-of-the-art AGCMs (MRI-AGCM and MetUM). We

109 compare the MetUM integrations at N96 (200-km mesh on the equator), N216 (90-km

110 mesh) and N512 (40-km mesh) that were used by Johnson et al. (2016) with an 
111 MRI-AGCM series at TL95 (180-km mesh on the equator), TL319 (60-km mesh), and

112 TL959 (20-km mesh) resolutions. Johnson et al. (2016) found that fine orography at

113 N512 improves orographic rainfall over the south Asian continent and the Somali Jet

114 wind speed is increased by the better resolution of the East African Highlands. Over the

115 Maritime Continent (MC), rainfall increases over land, while it decreases in the west

116 Pacific. Furthermore, Johnson et al. (2016) investigated the role of LPS on the rainfall

117 change over India and concluded that LPS contribute to slightly more rainfall over

118 northeast India at N512. In this paper, we compare this resolution sensitivity to the

119 sensitivity of the MRI-AGCM, and analyze similarities and differences. Section 2

120 describes the models used in this study. Section 3 shows the results of the seasonal

121 mean ASM and its resolution sensitivity. Section 4 presents the orographic effects and

122 intraseasonal variability. Upper tropospheric thickness and its seasonal evolution are

123 also investigated as a measurement of drivers of the ASM. Section 5 presents the

124 summary and a discussion of the results.

126 2. Methodology

127

128 2.1. Experiments in MRI-AGCM and MetUM

129 We make use of the MRI-AGCM3.2 model (Mizuta et al. 2012) developed at 130 20-km and 60-km horizontal resolutions, with 64 vertical levels (TL959L64 and 131 TL319L64). This model, in which an especially deep convective scheme was changed 132 from a relaxed Arakawa-Schubert scheme to a Tiedtke-like scheme proposed by 
133 Yoshimura et al. (2015), is an improved version of MRI-AGCM3.1 (Mizuta et al. 2006).

134 Using the 20-km resolution AGCM (MRI-AGCM3.2S), Murakami et al. (2012)

135 reported that the simulated intensity of global TCs was significantly improved, as

136 compared with results of the previous version (MRI-AGCM3.1S). These 20-km and

137 60-km AGCMs are used for studies of TCs (Murakami et al. 2012), global monsoon

138 (Endo et al. 2012) and East Asian monsoon (Kusunoki and Mizuta 2013) in the future

139 climate. An additional simulation of MRI-AGCM3.2 at 180-km horizontal resolution

140 (TL95L64) was performed for resolution sensitivity studies. In MRI-AGCM, the lower

141 boundary conditions are prescribed by observed monthly-mean SST and sea ice

142 concentration of the Met Office Hadley Centre Sea Ice and Sea Surface Temperature

143 version 1 (HadISST1; Rayner et al. 2003) for the period 1979-2003. To focus on

144 resolution sensitivity, we only changed the horizontal resolution while other settings

145 (i.e. vertical resolution and physical package) remain the same.

146 The configuration of the MetUM used here is the Global Atmosphere 3.0

147 (Walters et al. 2011) configuration of the atmospheric component of the HadGEM3

148 family. We used integrations from the UPSCALE simulation campaign (Mizielinski et

149 al. 2014) at three horizontal resolutions: approximately $40-\mathrm{km}, 90-\mathrm{km}$ and $200-\mathrm{km}$, and

15085 vertical levels (N512L85, N216L85, N96L85 respectively). The lower boundary

151 conditions are prescribed by the observed daily-mean SST and sea ice concentration of

152 the OSTIA product (Donlon et al. 2012) for the period 1985-2011. The UPSCALE

153 campaign simulations have previously been used for multiple resolution sensitivity

154 studies, such as the global and regional hydrological cycles (Demory et al. 2014; 
155 Schiemann et al. 2014; Vellinga et al. 2016), ASM (Johnson et al. 2016) and TCs

156 (Roberts et al. 2015). Similar to MRI-AGCM, only horizontal resolution was changed

157 between integrations. A detailed description of the integrations and model settings is

158 given in Mizielinski et al. (2014).

\subsection{Observational datasets}

The Japanese 55-year reanalysis (JRA-55, Kobayashi et al. 2015, $1.25^{\circ}$

162 resolution) provided by Japan Meteorological Agency (JMA) and CPC Merged

163 Analysis of Precipitation (CMAP, Xie and Arkin 1997, $2.5^{\circ}$ resolution) were used to

164 verify 1986-2003 in both AGCMs at all resolutions. Furthermore, we used Global

165 Precipitation Climatology Project version 1.2 (GPCP, Huffmann et al. 2001, $1^{\circ}$

166 resolution) in Section 4.2 to verify synoptic rainfall variability and Tropical Rainfall

167 Measuring Mission product 3B43v7 (TRMM, Huffman et al. $2007,0.25^{\circ}$ resolution) in

168 Section 4.1 to verify rainfall over orography. In these two observational datasets, due to

169 data coverage, different periods (1997-2012 in GPCP, and 1998-2012 in TRMM) were

170 analyzed. Except in Section 4.1, all datasets were re-gridded to N96 (approximately

$171 \quad 200-\mathrm{km}$ resolution).

173 2.3. Analysis methods

174 In Section 3, we used Taylor's skill scores to evaluate the model performance.

175 Using pattern correlation (R) and standard deviation ratio (SDR; GCM's value 176 normalized by observed value), Taylor (2001) proposed a skill score (S) to evaluate the 
177 GCM reproducibility,

$$
\mathrm{S}=\frac{4(1+R)^{4}}{(S D R+1 / S D R)^{2}\left(1+R_{0}\right)^{4}}, R_{0} \rightarrow 1 \ldots \text { (1). }
$$

179 . Higher S means higher reproducibility and if a GCM's performance is perfect (SDR $\rightarrow$ $180 \quad 1$ and $\mathrm{R} \rightarrow 1), \mathrm{S}=1$.

181 In Section 4.2, to investigate the resolution sensitivity of the intra-seasonal 182 variability, we define the BSISO index (21-61 day rainfall variability over $12-22^{\circ} \mathrm{N}$, $\left.18370-95^{\circ} \mathrm{E}\right)$ and calculate the lag covariance of intra-seasonal rainfall variability (21-61 184 day band-passed) onto the BSISO index (Ajayamohan et al. 2009) to assess the 185 characteristics of northward propagation of BSISO during boreal summer (Figure 10).

\section{3. Resolution sensitivity of the ASM seasonal mean}

188 First, in the ASM seasonal mean, we compare the June-July-August (JJA) 189 climatology of precipitation and $850 \mathrm{hPa}$ circulation in MRI-AGCM and MetUM. TL95 190 MRI-AGCM and N96 MetUM (Figure 1a and 1c) shows similar clockwise ASM 191 circulation at $850 \mathrm{hPa}$. However, their JJA precipitation pattern is quite different. In 192 TL95 MRI-AGCM, the precipitation maximum is over the Indian subcontinent and 193 South Asia, while in N96 MetUM, precipitation peaks in the equatorial Indian Ocean. 194 The difference between the AGCM biases (defined as 'AGCM minus CMAP') in 195 MRI-AGCM and MetUM is shown in Fig. 1b and 1d. Over the tropical Indian Ocean, 196 dry (wet) bias exists near the equator while wet and cyclonic (dry and anticyclonic) bias 197 appears over the northern hemisphere in MRI-AGCM (MetUM). Over the western 
198 Pacific, cyclonic bias appears south of Japan in both MRI-AGCM and MetUM.

199 Next, we investigate the resolution sensitivity of precipitation over the south

200 Asian monsoon domain. In MRI-AGCM, dry bias over the tropical Indian Ocean is 201 improved (Fig. 2a-2c). For example, mean bias over the tropical Indian Ocean $202\left(20^{\circ} \mathrm{S}-20^{\circ} \mathrm{N}, 40-100^{\circ} \mathrm{E}\right)$ is $0.62 \mathrm{~mm} \mathrm{day}^{-1}$ in TL95 and $-0.19 \mathrm{~mm} \mathrm{day}^{-1}$ in TL959 (Fig. 203 3a). On the other hand, the root mean square error (RMSE) (2.6 mm day ${ }^{-1}$ in TL95 and $2043.1 \mathrm{~mm} \mathrm{day}^{-1}$ in TL959) and the pattern correlation (0.80 in TL95 and TL959) are not 205 improved (Fig. $3 \mathrm{~b}$ and 3c). This is probably because some places show improvements, 206 but others do not and may even degrade, so the scores do not change. In MetUM, the 207 meridional dipole bias over the tropical Indian Ocean (wet bias on the equator and dry 208 bias around $10-20^{\circ} \mathrm{N}$ ) is improved (Fig. $2 \mathrm{~d}-2 \mathrm{f}$ ). However, on the basin-wide average $209\left(20^{\circ} \mathrm{S}-20^{\circ} \mathrm{N}, 40-100^{\circ} \mathrm{E}\right)$, mean bias $\left(0.12 \mathrm{~mm} \mathrm{day}^{-1}\right.$ in $\mathrm{N} 96$ and $0.08 \mathrm{~mm}^{-1 a y}{ }^{-1}$ in N512), 210 RMSE (3.9 mm day ${ }^{-1}$ in N96 and $3.6 \mathrm{~mm} \mathrm{day}^{-1}$ in N512), and pattern correlation (0.60 211 in N96 and 0.62 in N512) are not substantially improved (Fig. 3a-3c). Taylor's skill 212 scores also show that the scores are not improved in both MRI-AGCM and MetUM (Fig. 213 4a). Consistent with Johnson et al. (2016)'s results, the resolution sensitivity decreases 214 as resolution increases, so the resolution sensitivity of precipitation and $850 \mathrm{hPa}$ 215 circulation is larger from TL95 to TL319 in MRI-AGCM (N96 to N216 in MetUM), 216 than from TL319 to TL959 in MRI-AGCM (N216 to N512 in MetUM) (Fig. 2). 217 Resolution sensitivity of precipitation is different between MRI-AGCM and MetUM, 218 with a pattern correlation of 0.22 (0.21-0.24 in Jackknife method) over the Indian Ocean $219\left(20^{\circ} \mathrm{S}-20^{\circ} \mathrm{N}, 40-100^{\circ} \mathrm{E}\right)$. In MRI-AGCM, large off-equatorial precipitation increase 
220 appears both north and south of the equator. Particularly, a large precipitation increase

221 can be seen over the west of the Western Ghats and a cyclonic anomaly appears over the 222 Arabian Sea (Fig. 2a-2c). Precipitation also increases with resolution over the northern 223 Indian subcontinent and southern Indian Ocean around $0-10^{\circ} \mathrm{S}$. In MetUM, this 224 off-equatorial precipitation increase with resolution is less significant and a 225 precipitation decrease appears over the equator (Fig. 2d-2f). MRI-AGCM and MetUM share a similar resolution sensitivity of precipitation 227 over the western Pacific (Fig. 2c and 2f), with a pattern correlation of 0.48 (0.41-0.53 in 228 Jackknife method) over the western Pacific $\left(0-40^{\circ} \mathrm{N}, 120-180^{\circ} \mathrm{E}\right)$. At higher resolution, 229 precipitation decreases over the northwestern Pacific and northern MC, while it 230 increases over East Asia (around $20-40^{\circ} \mathrm{N}$ ) and the southern MC., An anticyclonic 231 circulation change associated with the precipitation decrease also appears over the 232 northwestern Pacific. Such anticyclonic circulation transports moisture from the tropics 233 to the East Asia and reinforces the Baiu-Meiyu front, which is consistent with previous 234 studies showing that high-resolution AGCMs can reproduce a more realistic 235 Baiu-Meiyu rainband (Kitoh and Kusunoki 2008). Taylor's skill scores (Fig. 4c) 236 quantitatively show that the scores over the Baiu-Meiyu front $\left(20-40^{\circ} \mathrm{N}, 120-150^{\circ} \mathrm{E}\right)$ are 237 improved in both MRI-AGCM (0.20 in TL95 and 0.50 in TL959) and MetUM (0.20 in $238 \quad$ N96 and 0.27 in N512).

239 In order to investigate the resolution sensitivity of precipitation, we analyze the 240 moisture budget at different resolutions (Figures 5 through 7). Fig. 5a and 5e show JJA 241 climatology of TL95 MRI-AGCM and N96 MetUM moisture transport and 
242 convergence. The clockwise moisture transport of ASM occurs in both models. On the

243 other hand, moisture convergence maximum over the Indian subcontinent appears in

244 MRI-AGCM, while convergence stays over the equatorial Indian Ocean in MetUM.

245 Over the southern MC, MetUM shows a large increase in moisture convergence (Fig.

246 5h), which is less significant in MRI-AGCM (Fig. 5d). Moisture budget analysis also

247 exhibits these features (Fig. 6d). Compared to the moisture convergence changes,

248 surface evaporation increases only slightly with resolution over the MC in MRI-AGCM,

249 while it does not change in MetUM (Fig. 6c). Over the northern Indian Ocean, similar

250 to the pattern of precipitation change (Fig. 2), a large moisture convergence increase

251 occurs over the west of the Western Ghats and Northern Indian Ocean in MRI-AGCM

252 (Fig. 5d), while this is less significant in the MetUM where increased divergence

253 appears over the equator (Fig. 5h). It should be noted that westward moisture flux

254 anomaly appears over the South China Sea and Bay of Bengal in both models, which is

255 probably related to the anticyclonic circulation anomaly seen in Fig. 2 and the decreased

256 diabatic heating in the west Pacific.

257 Johnson et al. (2016) showed in the MetUM that decreasing precipitation over

258 the northern Maritime Continent/west Pacific and increasing precipitation over the

259 southern Maritime Continent were related to changes in moisture flux convergence.

260 Following their study, we applied an area-integrated moisture budget analysis over their

261 Maritime Continent regions and show the results in Figure 6b-6d. In MRI-AGCM, the

262 precipitation decrease (and moisture convergence decrease) with resolution is consistent

263 with MetUM over the northern box. In MRI-AGCM (MetUM), precipitation decreases 
264 from $9.67 \mathrm{~mm} \mathrm{day}^{-1}$ in TL95 (7.73 mm day ${ }^{-1}$ in N96) to $8.73 \mathrm{~mm} \mathrm{day}^{-1}$ in TL959 (6.22

$265 \mathrm{~mm} \mathrm{day}^{-1}$ in N512). Moisture convergence in MRI-AGCM (MetUM) also decreases 266 with increasing resolution: $5.05 \mathrm{~mm} \mathrm{day}^{-1}$ in TL95 (3.01 mm day ${ }^{-1}$ in N96) to $4.11 \mathrm{~mm}$ 267 day $^{-1}$ in TL959 (1.85 mm day ${ }^{-1}$ in N512). In contrast, precipitation and moisture 268 convergence tendencies in southern box are different between these AGCMs. In MetUM, 269 the precipitation increase from $5.5 \mathrm{~mm}^{-1}$ day $^{-1}$ in N96 to $6.5 \mathrm{~mm}^{-1 a y}{ }^{-1}$ in N512 is mainly 270 due to an increase in moisture convergence $\left(0.5 \mathrm{~mm}^{-1} \mathrm{yy}^{-1}\right.$ in $\mathrm{N} 96$ and $1.5 \mathrm{~mm}^{-1 a y}{ }^{-1}$ in 271 N512). On the other hand, precipitation $\left(5.2 \mathrm{~mm} \mathrm{day}^{-1}\right.$ in TL95 and $5.3 \mathrm{~mm}$ day $^{-1}$ in 272 TL959) and moisture convergence (0.3 mm day ${ }^{-1}$ in TL95 and TL959) are not sensitive 273 to resolution in MRI-AGCM.

274 To examine the difference in the resolution sensitivity of precipitation in the 275 Indian Ocean, we also perform a moisture budget analysis for the regions outlined in 276 Fig. 6a. Over the southern Indian Ocean (around $60-90^{\circ} \mathrm{E}, 0-10^{\circ} \mathrm{S}$ ), the precipitation 277 increase is more significant in MRI-AGCM than in MetUM. Over the Northern Indian 278 Ocean (Fig. 6e-6g), increasing precipitation (and increasing moisture convergence) is 279 clear in MRI-AGCM. High-resolution MetUM also shows a slight precipitation and 280 moisture convergence increase in the northern box. However, there are large 281 inter-model differences in the low-resolution climatology in these two models. Moisture 282 converges (diverges) over the northern (southern) region in MRI-AGCM while the 283 opposite occurs in MetUM (Fig. 6e-6g).

284 To investigate the origin of the different behavior of moisture budget over the 285 southern MC, Figure 7 shows averaged moisture flux into and out of the 
286 southern/northern MC and equatorial IO boxes (Fig. 7a). In MetUM, the increase of

287 moisture in finer-resolution over the southern MC is mainly caused by the decrease of 288 cross equatorial moisture flux (Fig. 7e-7g). On the other hand, in MRI-AGCM, change 289 of cross equatorial moisture flux is smaller than in MetUM (Fig. 7b-7d). Furthermore, 290 difference in the moisture supply across $160^{\circ} \mathrm{E}$ and moisture loss across $90^{\circ} \mathrm{E}$ seems 291 important. Across $160^{\circ} \mathrm{E}$, moisture supply decreases (increases) in MRI-AGCM 292 (MetUM) with higher resolution, which partly contributes to the different resolution 293 sensitivity of moisture convergence between two AGCMs over the southern MC box.

294 This difference over the southern MC may be related to differences in the 295 southern IO. In MRI-AGCM, budget of southern equatorial IO box shows distinct 296 decrease of cross equatorial moisture flux, which causes increase of moisture 297 particularly from TL95 to TL319 (Fig. 7c). Moisture flux across $90^{\circ} \mathrm{E}$ increases 298 (decreases) moisture over the southern equatorial IO (southern MC).

\section{4. What contributes to the resolution sensitivity of the ASM seasonal mean?}

301 The previous section motivates a question: why is the resolution sensitivity of 302 precipitation similar over the MC and west Pacific, but different over the Indian Ocean 303 and India in the two models? To answer this, we examine possible mechanisms driving 304 the resolution sensitivity, including better resolution of orography, better resolution of 305 intraseasonal/synoptic variability and the resolution sensitivity of the meridional 306 temperature gradient that drives the monsoon. 
High-resolution AGCMs are able to represent steep topography over south Asia

310 (Figure 8) and MC (Figure 9), which may affect the simulation of precipitation and

311 circulation. In both MRI-AGCM and MetUM, sharper rainfall peaks appear on the

312 western side of mountains at higher resolutions (Fig. $8 \mathrm{~b}$ and $8 \mathrm{~d}$ ). The monsoon westerly

313 wind intersects the Western Ghats $\left(75^{\circ} \mathrm{E}\right)$, Arakan Yoma $\left(90-95^{\circ} \mathrm{E}\right)$, Bilauktang $\left(100^{\circ} \mathrm{E}\right)$,

314 Annam Cordillera $\left(110^{\circ} \mathrm{E}\right)$, and Cordillera Central $\left(120^{\circ} \mathrm{E}\right)$. Precipitation is clearly

315 intensified around these mountains in TL959 and TL319 in MRI-AGCM (N512 and

316 N216 in MetUM), while TL95 MRI-AGCM and N96 MetUM cannot represent such

317 steep orography and the precipitation is smoothed (Fig. 8). Orography-induced

318 precipitation can be also seen in the MC. Fig. 9 shows that rainfall increases over the

319 mountains of New Guinea in the high-resolution AGCMs (around 5 ${ }^{\circ}$ S, Fig. 9b and 9d).

320 Although there is observation uncertainty, AGCMs are too wet over the land because of

321 the orography (Fig. 9b and 9d). The spatial distribution of precipitation over this area is

322 probably better at high resolution, but precipitation is more intense because of the

323 steepness of the mountains, causing a larger drag. High-resolution observation (TRMM)

324 also shows orography-induced rainfall, which can not be reproduced in

325 coarse-resolution AGCM (Fig. 8 and 9).

As mentioned in Section 3, in both models, rainfall decreases north of the

327 Maritime Continent. Johnson et al. (2016) hypothesized that increased resolution of the

328 orography of the Maritime Continent and Indochina created this precipitation decrease

329 through increasing moisture convergence over the orography, which reduces the 
330 westerly and southerly moisture transport into the west Pacific. As mentioned in Section

3313 , the resolution sensitivity of westerly moisture flux into the northern Maritime

332 Continent is larger in the MRI-AGCM than the resolution sensitivity of southerly

333 moisture flux. In the MRI-AGCM, the change in westerly moisture flux could be related

334 to the increased rainfall in the Indian Ocean basin. The lack of a precipitation increase

335 over the southern Maritime Continent in MRI-AGCM is likely due to the increase in

336 moisture convergence over the southern Indian Ocean, which is not present in MetUM.

337 It is not clear whether the same mechanisms are leading to the decrease in precipitation

338 in the west Pacific in both GCMs, and this would be an interesting subject for future

339 sensitivity experiments.

\subsection{Synoptic and Intra-seasonal variations over India}

342 Intra-seasonal variability can be decomposed into three modes: BSISO (21-61

343 day; Yasunari 1980, Jiang et al. 2004, Ajayamohan et al. 2009), biweekly-mode (9-21

344 day; Murakami 1976, Krishnamurti and Ardanuy 1980, Annamalai and Slingo 2001),

345 and LPS (3-9 day; Mak 1987, Goswami et al. 2003). The lead-lag covariance of

346 precipitation over $70-95^{\circ} \mathrm{E}$ onto the BSISO index exhibits the characteristics of

347 northward propagation of BSISO during boreal summer (Figure 10). The northward

348 propagation with about 50-day period is clear in both MRI-AGCM and MetUM (Fig.

349 10a-10d), consistent with previous studies (Ajayamohan et al. 2009). In MetUM, there

350 is little difference in the BSISO propagation between N96 (Fig. 10c) and N512 (Fig.

351 10d). In MRI-AGCM, BSISO rainfall in TL959 (Fig. 10b) shifts slightly northward 
352 (around $20^{\circ} \mathrm{N}$ ) compared to TL95 (Fig. 10a), but there is little change in amplitude.

353 Therefore, the BSISO activity has very little resolution sensitivity in either GCM.

354 Another possible driver of the resolution sensitivity of rainfall and circulation is 355 synoptic variability. For example, high-resolution AGCMs often improve the 356 representation of LPS over the northern Indian Ocean (Stowasser et al. 2009, Sabin et al. 357 2013, Johnson et al. 2016). Figure 11 shows the standard deviation of 358 synoptic-timescale (3-9 day band-passed) rainfall variability. The intra-seasonal 359 variability over central India increases substantially in the high-resolution (TL959) 360 MRI-AGCM (Fig. 11c). In N512 MetUM, synoptic timescale variability increases 361 (decreases) slightly over Bangladesh (ocean, e.g. Bay of Bengal), which is consistent 362 with the shift of the synoptic systems (Fig. 11f), shown using LPS tracking in Johnson 363 et al. (2016). The larger increase synoptic variability in MRI-AGCM than in MetUM 364 partly explains why the resolution sensitivity of precipitation is different in the two 365 GCMs over India and the Indian Ocean. An increase in LPS increases condensation 366 heating over India and the atmospheric response to this heating can increase the 367 moisture transport to the continent. These processes may act as a positive feedback to 368 enhance the precipitation. Observed daily precipitation (GPCP, 1997-2012) in Figure 12 369 shows that too much (little) synoptic rainfall variability appears over the southern 370 (northern) subcontinent in TL95 MRI-AGCM (Fig. 12b) while synoptic rainfall 371 variability is generally too small over India in N96 MetUM (Fig. 12c). The resolution 372 sensitivity of LPS (Fig. 11), has the opposite sign of the bias, particularly in the 373 MRI-AGCM, and consequently improves the bias of synoptic rainfall variability over 
India.

\subsection{Upper tropospheric warming}

Meridional thermal gradient (MTG) in the upper troposphere is a major driver of

378 the south Asian monsoon (e.g. Li and Yanai 1996, Xavier et al. 2007). In boreal summer,

379 warming over the south Asian continent causes reversal of the MTG and can be used to

380 define a south Asian monsoon (SAM) onset date. To investigate the resolution

381 sensitivity of the upper tropospheric warming, the resolution sensitivity of the 200-600

$382 \mathrm{hPa}$ tropospheric thickness is shown in Figure 13. As resolution increases, tropospheric

383 cooling appears over the tropics (from $30^{\circ} \mathrm{S}$ to $30^{\circ} \mathrm{N}$ ) in MRI-AGCM and over the

384 Indo-Pacific in MetUM. Over the northwestern Pacific (NWP) and South China Sea

385 (SCS) region $\left(0-20^{\circ} \mathrm{N}, 105-180^{\circ} \mathrm{E}\right), 200-600 \mathrm{hPa}$ thickness change is larger in

386 MRI-AGCM (-23.08 $\mathrm{m}$ in MRI-AGCM, while $-5.02 \mathrm{~m}$ in MetUM, equal to $21.8 \%$ of

387 MRI-AGCM). Such cooling seems to originate from the NWP, consistent with rainfall

388 decrease and anti-cyclonic anomaly. Tropospheric cooling spreads into the entire tropics

389 zonally, and this enhances land-sea thermal contrast over the South Asian continent.

390 Such thermal contrast change is larger in MRI-AGCM (Fig. 13a-c) than in MetUM (Fig. 391 13d-f).

392 To diagnose whether the resolution sensitivity of heating over the NWP is 393 important for this tropospheric cooling response, we investigate the Matsuno-Gill like 394 response (Matsuno 1966, Gill 1980) to regional heating using a linear baroclinic model 395 (LBM), similar to Ogata (2013). LBMs are derived from the linearized atmospheric 
396 primitive equation using a sigma coordinate system. The LBM used here has a rest 397 background state (i.e. zero background velocity), a zonally averaged equatorial thermal 398 structure (i.e. uniform stratification) derived from JRA-55, and a resolution of $2.5^{\circ}$ 399 horizontally with 14 vertical levels. Heating was estimated for each model individually 400 from the precipitation pattern seen in Fig. $2 \mathrm{c}$ and $2 \mathrm{f}$, and is shown in Figure $14 \mathrm{a}$ and c.

401 To define the vertical profile, a heating maximum of $0.47 \mathrm{~K} \mathrm{day}^{-1}$ per $1 \mathrm{~mm}$ day $^{-1}$ is 402 assumed at $600 \mathrm{hPa}$ and the heating reachs zero at 200 and $1000 \mathrm{hPa}$. Figure 14 shows 403 the response to the change in heating when resolution is increased in the MRI-AGCM 404 and MetUM. In MRI-AGCM and the MetUM, response to western Pacific forcing $405\left(30^{\circ} \mathrm{S}-30^{\circ} \mathrm{N}, 120-180^{\circ} \mathrm{E}\right.$ in Fig. $\left.14 \mathrm{a}, \mathrm{c}\right)$ contributes to tropospheric cooling on $200-600$ $406 \mathrm{hPa}$ due to the rainfall decrease (Fig. 14b, d), but in the MetUM the response is much 407 weaker. It should be noted that key features of tropospheric cooling in Fig. 13 (e.g. 408 larger tropospheric cooling in MRI-AGCM) cannot be reproduced in this linear model 409 by the Indian Ocean forcing (not shown). Particularly the effect of warming by the 410 Indian Ocean forcing may be overestimated.

411 Figure 15 shows the seasonal evolution of MTG, as defined by Xavier et al. 412 (2007): the difference between the 200-600 hPa upper tropospheric thickness (units: $\mathrm{m}$ ) 413 averaged over south Asia $\left(5-35^{\circ} \mathrm{N}, 40-100^{\circ} \mathrm{E}\right)$ and the equatorial Indian ocean $414\left(15^{\circ} \mathrm{S}-5^{\circ} \mathrm{N}, 40-100^{\circ} \mathrm{E}\right)$. In both MRI-AGCM and MetUM, the MTG changes sign from 415 negative to positive between May and June. During May-June, the MTG is stronger in 416 TL959 MRI-AGCM than in TL95 MRI-AGCM, and similarly MTG in N512 MetUM is 417 stronger than in N96 MetUM. Interestingly, resolution sensitivity is comparable in 
418 magnitude to the inter-model difference (Fig. 15). During August-September, in contrast,

419 there is little resolution sensitivity and the inter-model difference is larger. In reanalysis 420 (JRA-55), sign reversal of MTG starts earlier and the MTG is larger throughout the 421 season. This means the higher-resolution GCMs are more accurate (Fig. 15) than the 422 low-resolution. The stronger MTG in the high-resolution MRI-AGCM is likely related 423 to the increasing SAM precipitation. MTG is also linked to the easterly vertical wind 424 shear between U850 and U200, which contributes to synoptic variability through an 425 internal instability condition (Charney and Stern 1962, Shukla 1978). The larger MTG 426 in the high-resolution MRI-AGCM may consequently be related to the increase in 427 synoptic variability seen in Fig. 11 and the associated with increased precipitation from 428 monsoon LPS.

\section{5. Summary and discussion}

431 In this study, the resolution sensitivity of the ASM in two AGCMs, MRI-AGCM 432 and MetUM, is investigated and compared. We compare the MetUM series at N96 433 (200-km mesh on the equator), N216 (90-km mesh) and N512 (40-km mesh), with the 434 MRI-AGCM series at TL95 (180-km mesh on the equator), TL319 (60-km mesh) and 435 TL959 (20-km mesh).

Both MRI-AGCM and MetUM share a similar precipitation decrease over the

437 western Pacific with increasing resolution. Associated with the precipitation decrease, 438 low-level anti-cyclonic circulation change appears over the northwestern Pacific. On the 439 other hand, over the Indian Ocean, the resolution sensitivity of precipitation is quite 
440 different between the two AGCMs. In MRI-AGCM, a large precipitation increase

441 appears off the equator, while such off-equatorial precipitation increase is less 442 significant and precipitation decreases over the equator in MetUM. The resolution 443 sensitivity is not a clear improvement on the mean state in either GCM, and the 444 resolution sensitivity is not proportional to the GCM bias. To examine the difference in 445 the resolution sensitivity of precipitation, we also performed a moisture budget analysis.

446 Over the Indian Ocean, there are large inter-model differences in the low-resolution 447 climatology in these two models. Moisture converges (diverges) over the northern 448 (southern) region in MRI-AGCM while the opposite occurs in MetUM. Over the 449 Maritime Continent, decrease of cross equatorial moisture flux which is important for 450 precipitation in MetUM (Johnson et al. 2016) is small in MRI-AGCM. As possible causes of the resolution sensitivity of the ASM, orographic effect, 452 intra-seasonal variability, and changes to the meridional temperature gradient have been 453 considered. Both high-resolution AGCMs (TL959 and N512) can represent steep 454 topography, which anchors rainfall pattern over south Asia and the Maritime Continent. 455 Furthermore, increase of synoptic rainfall variability by low pressure systems at TL959 456 and N512 seems to contribute to the rainfall increase over the land, but is much more 457 significant in the MRI-AGCM. Additionally, an upper-tropospheric cooling over the 458 tropics, linked to rainfall and diabatic heating changes over the west Pacific (Section 459 4.3), causes a stronger meridional thermal gradient at high resolution, particularly in 460 MRI-AGCM, and improves the seasonal evolution of the MTG. The larger resolution 461 sensitivity of LPS and the MTG in the MRI-AGCM than the MetUM may be related, 
462 and likely contribute to the larger resolution sensitivity of Indian precipitation in the 463 MRI-AGCM.

464 There are, however, large differences in circulation and precipitation over the 465 Indian Ocean between MRI-AGCM and MetUM. On the equatorial Indian Ocean, there 466 is a negative rainfall anomaly in MRI-AGCM. In contrast, a positive rainfall anomaly 467 appears around $10-20^{\circ} \mathrm{N}$ (Figure 16). These results suggest that the anti-symmetric 468 meridional dipole anomaly over the Indian Ocean generates a clockwise circulation and, 469 in presence of a positive feedback, the westerly response to the diabatic heating around $470 \quad 10-20^{\circ} \mathrm{N}$ further generates a condensation heating through moisture supply over south 471 Asia. Such mean state difference in the Indian monsoon between MRI-AGCM and 472 MetUM may cause the different resolution sensitivity through the interaction with 473 topography (e.g. larger rainfall increase in MRI-AGCM than in MetUM on the western 474 side of the mountains; Fig. 2 and 8), and synoptic intra-seasonal variability by moist 475 instability (e.g. different patterns in synoptic rainfall variability between MRI-AGCM 476 and MetUM; Fig. 11). It should be noted that the inter-model difference becomes 477 smaller at high resolution over the equatorial Indian Ocean (Fig. 16b and 16c).

478 In Section 4.1 and 4.2, we discussed orographic and non-orographic effects on 479 resolution sensitivity. However, quantitative evaluation of their effect is still unclear. 480 Sensitivity experiments would help quantify the relative importance of orographic and 481 non-orographic effects. In MetUM, for example, previous study has reported that annual 482 mean precipitation over the $\mathrm{MC}$ is sensitive to the representation of coastal lines 483 through mean circulation change (Schiemann et al. 2014). 
485 sensitivity of the ASM simulation between the MetUM and the MRI-AGCM. However,

486 we have also highlighted some major differences, which are likely due to the differences

487 in the model physics schemes, which also cause different model mean biases. These

488 results highlight the necessity of multi-model assessments regarding the role of 489 resolution in climate simulations, such as the upcoming EU Horizon 2020 490 PRIMAVERA (PRocess-based climate sIMulation: AdVances in high-resolution 491 modelling and European climate Risk Assessment) project.

\section{Acknowledgements} SJJ and RS were supported by the Joint Weather and Climate Research

496 Programme (JWCRP), a partnership between the Natural Environment Research 497 Council (NERC) and the UK Met Office, under University of Reading Contract 498 R8/H9/37. RS and MED were supported by the National Centre for Atmospheric 499 Science Climate directorate (NCAS-Climate), a collaborative centre of NERC. MED 500 acknowledges NCAS Climate contract R8/H12/83/001 for the High Resolution Climate 501 Modelling programme. The MetUM simulations analysed here were produced as part of 502 the UPSCALE project (information about data access is available from the project 503 website: http://proj.badc.rl.ac.uk/upscale). We thank the UPSCALE team (P.L. Vidale 504 [PI], M. J. Roberts, M. S. Mizielinski, J. Strachan, RS, MED), the large team of model 505 developers, infrastructure experts and all the other essential components required to 
506 conduct the UPSCALE campaign, in particular the PRACE infrastructure and the

507 Stuttgart HLRS supercomputing centre, as well as the STFC CEDA service for data 508 storage and analysis using the JASMIN platform. We also acknowledge use of the 509 MONSooN system, a collaborative facility supplied under JWCRP, and HECToR, the

510 UK national supercomputer. Numerical experiments of MRI-AGCM were executed on

511 the Earth Simulator of the Japan Agency for Marine-Earth Science and Technology

512 (JAMSTEC). This work was conducted under the SOUSEI Program of the Ministry of

513 Education, Culture, Sports, Science, and Technology (MEXT) of Japan.

515 Reference

516 Ajayamohan RS, Rao SA, Luo J-J, Yamagata T (2009) Influence of Indian Ocean 517 Dipole on boreal summer intraseasonal oscillations in a coupled general 518 circulation model. J Geophys Res 114: D06119. doi:10.1029/2008JD011096

519 Annamalai H, Slingo JM (2001) Active/break cycles: Diagnosis of the intraseasonal 520 variability of the Asian summer monsoon. Clim Dyn 18: 85-102

521 Chang CP, Zhang YS, Li T (2000) Interannual and interdecadal variations of the East 522 Asian summer monsoon and tropical Pacific SSTs. Part I: Roles of the subtropical $523 \quad$ ridge. J. Clim 13: 4310-4325

524 Charney JG, Stern ME (1962) On the stability of internal baroclinic jets in a rotating 525 atmosphere. J Atmos Sci 19(2): 159-172

526 Cho C, Li R, Wang SY, Yoon JH, Gillies RR (2015) Anthropogenic footprint of climate 527 change in the June 2013 northern India flood. Clim Dyn 46: 1-9 
528 Demory ME, Vidale PL, Roberts MJ, Berrisford P, Strachan J, Schiemann R, 529 Mizielinski MS (2014) The role of horizontal resolution in simulating drivers of 530 the global hydrological cycle. Clim Dyn 42(7-8): 2201-2225

531 Donlon CJ, Martin M, Stark J, Roberts-Jones J, Fiedler E, Wimmer W (2012) The 532 operational sea surface temperature and sea ice analysis (OSTIA) system. Remote $533 \quad$ Sens Environ 116: 140-158

534 Endo H, Kitoh A, Ose T, Mizuta R, Kusunoki S (2012) Future changes and 535 uncertainties in Asian precipitation simulated by multiphysics and multi-sea $536 \quad$ surface temperature ensemble experiments with high-resolution Meteorological 537 Research Institute atmospheric general circulation models (MRI-AGCMs). J 538 Geophys Res 117: D16118. doi:10.1029/2012JD017874

539 Gill A (1980) Some simple solutions for heat-induced tropical circulation. Quart J Roy $540 \quad$ Meteor Soc 106(449): 447-462

541 Goswami BN, Ajayamohan RS, Xavier PK, Sengupta D (2003) Clustering of synoptic 542 activity by Indian summer monsoon intraseasonal oscillations. Geophys Res Lett 543 30(8). doi: 10.1029/2002GL016734

544 Huffman GJ et al (2001) Global precipitation at one-degree daily resolution from $545 \quad$ multisatellite observations. J Hydrometeor 2(1): 36-50

546 Huffman GJ et al (2007) The TRMM multisatellite precipitation analysis (TMPA): 547 Quasi-global, multiyear, combined-sensor precipitation estimates at fine scales. J $548 \quad$ Hydrometeor 8(1): 38-55

549 He C, Zhou T (2015) Decadal change of the connection between summer western North 
552 Jha B, Krishnamurti TN, Christides Z (2000) A note on horizontal resolution 553 dependence for monsoon rainfall simulations. Meteor Atmos Phys 74(1-4): 11-17

554 Jiang X, Li T, Wang B (2004) Structures and mechanisms of the northward propagating $555 \quad$ boreal summer intraseasonal oscillation. J Clim 17: 1022-1039

556 Johnson SJ et al (2016) The resolution sensitivity of the South Asian monsoon and $557 \quad$ Indo-Pacific in a global $0.35^{\circ}$ AGCM. Clim Dyn 46(3): 807-831

558 Joseph S et al (2015) North Indian heavy rainfall event during June 2013: diagnostics 559 and extended range prediction. Clim Dyn 44(7-8): 2049-2065

560 Kitoh A, Kusunoki S (2008) East Asian summer monsoon simulation by a 20-km mesh 561 AGCM. Clim Dyn 31(4): 389-401

562 Kobayashi C, Sugi M (2004) Impact of horizontal resolution on the simulation of the 563 Asian summer monsoon and tropical cyclones in the JMA global model. Clim Dyn 23(2): 165-176

565 Kobayashi S et al (2015) The JRA-55 reanalysis: general specifications and basic characteristics. J Met Soc Jpn 93(1): 5-48

567 Krishnamurti TN, Ardanuy P (1980) The 10 to 20-day westward propagating mode and 568 "Breaks in the Monsoons". Tellus 32(1): 15-26

569 Kusunoki S, Mizuta R (2013) Changes in precipitation intensity over East Asia during the 20th and 21 st centuries simulated by a global atmospheric model with a $60 \mathrm{~km}$ grid size. J Geophys Res 118(19). doi:10.1002/jgrd.50877 
572 Lau WK, Kim KM (2012) The 2010 Pakistan flood and Russian heat wave: 573 Teleconnection of hydrometeorological extremes. J Hydromet 13(1): 392-403

574 Li C, Yanai M (1996) The onset and interannual variability of the Asian summer 575 monsoon in relation to land-sea thermal contrast. J Clim 9(2): 358-375

576 Liu P et al (2009) Tropical Intraseasonal Variability in the MRI-20km60L AGCM. J Clim 22(8): 2006-2022

578 Mak M (1987) Synoptic-scale disturbances in the summer monsoon. In: Monsoon $579 \quad$ Meteorology. Edited by Chang CP, Krishnamurti TN. Oxford Univ Press, pp 435$580 \quad 460$

581 Martin GM (1999) The simulation of the Asian summer monsoon, and its sensitivity to 582 horizontal resolution, in the UK Meteorological Office Unified Model. Quart J Roy Meteor Soc 125(557): 1499-1525

584 Matsuno T (1966) Quasi-geostrophic motions in the equatorial area. J Met Soc Jpn 585 44(1): $25-43$

586 Mizielinski MS et al (2014) High-resolution global climate modelling: the UPSCALE 587 project, a large-simulation campaign. Geosci Model Dev 7(4): 1629-1640

588 Mizuta R et al (2006) 20-km-mesh global climate simulations using JMA-GSM 589 model-Mean climate states. J Met Soc Jpn 84(1): 165-185

590 Mizuta R et al (2012) Climate simulations using MRI-AGCM3.2 with 20-km grid. J 591 Met Soc Jpn 2 90(0): 233-258

592 Murakami M (1976) Analysis of Summer Monsoon Fluctuations over India. J Met Soc 593 Jpn 54: 15-31 
594 Murakami H, Sugi M (2010) Effect of model resolution on tropical cyclone climate $595 \quad$ projections. SOLA 6: 73-76

596 Murakami H et al (2012) Future changes in tropical cyclone activity projected by the new high-resolution MRI-AGCM. J Clim 25(9): 3237-3260

598 Ogata T (2013) The Effect of the Australian-Maritime Continents on the Indian Ocean Dipole Mode in an Idealized Coupled General Circulation Model. SOLA 9(0): $84-88$

601 Ogata T et al (2014) Projected future changes in the Asian Monsoon: A comparison of 602 CMIP3 and CMIP5 model results. J Met Soc Jpn 92(3): 207-225

603 Oouchi $\mathrm{K}$ et al (2006) Tropical cyclone climatology in a global-warming climate as 604 simulated in a $20 \mathrm{~km}$-mesh global atmospheric model: Frequency and wind 605 intensity analyses. J Met Soc Jpn 84(2): 259-276

606 Rayner NA et al (2003) Global analyses of sea surface temperature, sea ice, and night 607 marine air temperature since the late nineteenth century. J Geophys Res 108(D14). 608 doi: $10.1029 / 2002 J D 002670$

609 Roberts MJ et al (2015) Tropical Cyclones in the UPSCALE Ensemble of 610 High-Resolution Global Climate Models. J Clim 28(2): 574-596

611 Sabeerali CT, Ramu Dandi A, Dhakate A, Salunke K, Mahapatra S, Rao SA (2013) Simulation of boreal summer intraseasonal oscillations in the latest CMIP5 coupled GCMs. J Geophys Res 118(10): 4401-4420

614 Sabin TP, Krishnan R, Ghattas J, Denvil S, Dufresne JL, Hourdin F, Pascal T (2013) 615 High resolution simulation of the South Asian monsoon using a variable 
617 Schiemann R, Demory ME, Mizielinski MS, Roberts MJ, Shaffrey LC, Strachan J, 618 Vidale PL (2014) The sensitivity of the tropical circulation and Maritime 619 Continent precipitation to climate model resolution. Clim Dyn 42(9-10): $620 \quad 2455-2468$

621 Shukla J (1978) CISK-barotropic-baroclinic instability and the growth of monsoon depressions. J Atmos Sci 35(3): 495-508

623 Sperber KR, Hameed S, Potter GL, Boyle JS (1994) Simulation of the northern summer 624 monsoon in the ECMWF model: sensitivity to horizontal resolution. Mon $625 \quad$ Weather Rev 122(11): 2461-2481

626 Sperber KR, Annamalai H, Kang IS, Kitoh A, Moise A, Turner A, Wang B, Zhou T 627 (2013) The Asian summer monsoon: an intercomparison of CMIP5 vs. CMIP3 simulations of the late 20th century. Clim Dyn 41(9-10): 2711-2744

629 Stephenson DB, Chauvin F, Royer JF (1998) Simulation of the Asian summer monsoon and its dependence on model horizontal resolution. J Met Soc Jpn 76(2): 237-265

631 Stowasser M, Annamalai H, Hafner J (2009) Response of the South Asian Summer 632 Monsoon to Global Warming: Mean and Synoptic Systems. J Clim 22(4): $633 \quad 1014-1036$

634 Taylor KE (2001) Summarizing multiple aspects of model performance in a single 635 diagram. J Geophys Res 106(D7): 7183-7192

636 Vellinga M, Roberts M, Vidale PL, Mizielinski MS, Demory ME, Schiemann R, 637 Strachan J, Bain C (2016) Sahel decadal rainfall variability and the role of model 
638 horizontal resolution. Geophys Res Lett 43. doi:10.1002/2015GL066690

639 Walters DN et al (2011) The Met Office Unified Model global atmosphere 3.0/3.1 and 640 JULES global land 3.0/3.1 configurations. Geosci Model Dev 4(4): 919-941

641 Xavier PK, Marzin C, Goswami BN (2007) An objective definition of the Indian 642 summer monsoon season and a new perspective on the ENSO-monsoon 643 relationship. Quart J Roy Meteor Soc 133(624): 749-764

644 Xie P, Arkin PA (1997) Global precipitation: A 17-year monthly analysis based on 645 gauge observations, satellite estimates, and numerical model outputs. Bull Amer $646 \quad$ Meteor Soc 78(11): 2539-2558

647 Xie SP, Xu H, Saji NH, Wang Y, Liu WT (2006) Role of Narrow Mountains in 648 Large-Scale Organization of Asian Monsoon Convection. J Clim 19(14): $649 \quad 3420-3429$

650 Yasunari T (1980) A quasi-stationary appearance of 30- to 40-day period in the 651 cloudiness fluctuations during the summer monsoon over India. J Met Soc Jpn 58: $225-229$

653 Yoshimura H, Mizuta R, Murakami H (2015) A spectral cumulus parameterization 654 scheme interpolating between two convective updrafts with semi-Lagrangian 655 calculation of transport by compensatory subsidence. Mon Weather Rev 143(2): 656 $597-621$

657 658 
Click here to view linked References
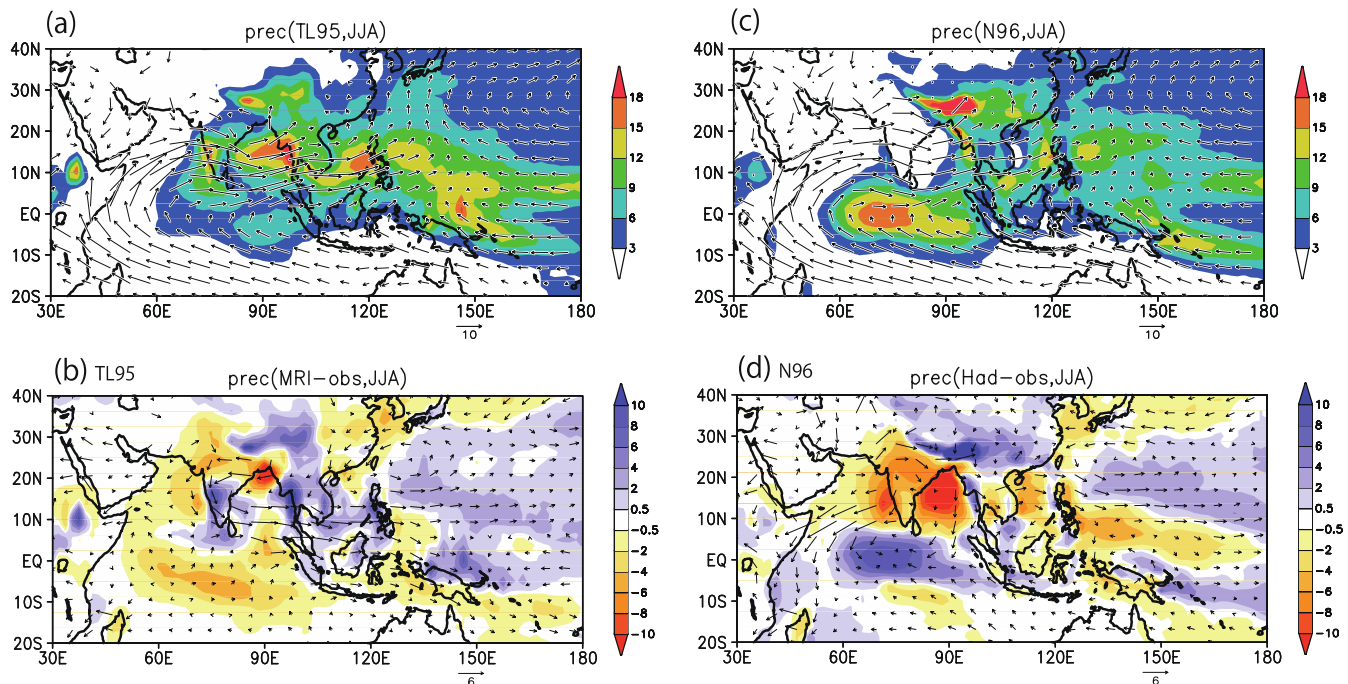

2 Figure 1: JJA precipitation (shaded, units: $\mathrm{mm} \mathrm{day}^{-1}$ ) and horizontal $850 \mathrm{hPa}$ wind

3 (vector, units: $\mathrm{m} \mathrm{s}^{-1}$ ) in (a) TL95 MRI-AGCM and (c) N96 MetUM. Difference between

(b) TL95 MRI-AGCM, (d) N96 MetUM and CMAP observed precipitation / JRA-55

5 reanalysis wind.

6

7

8

9 

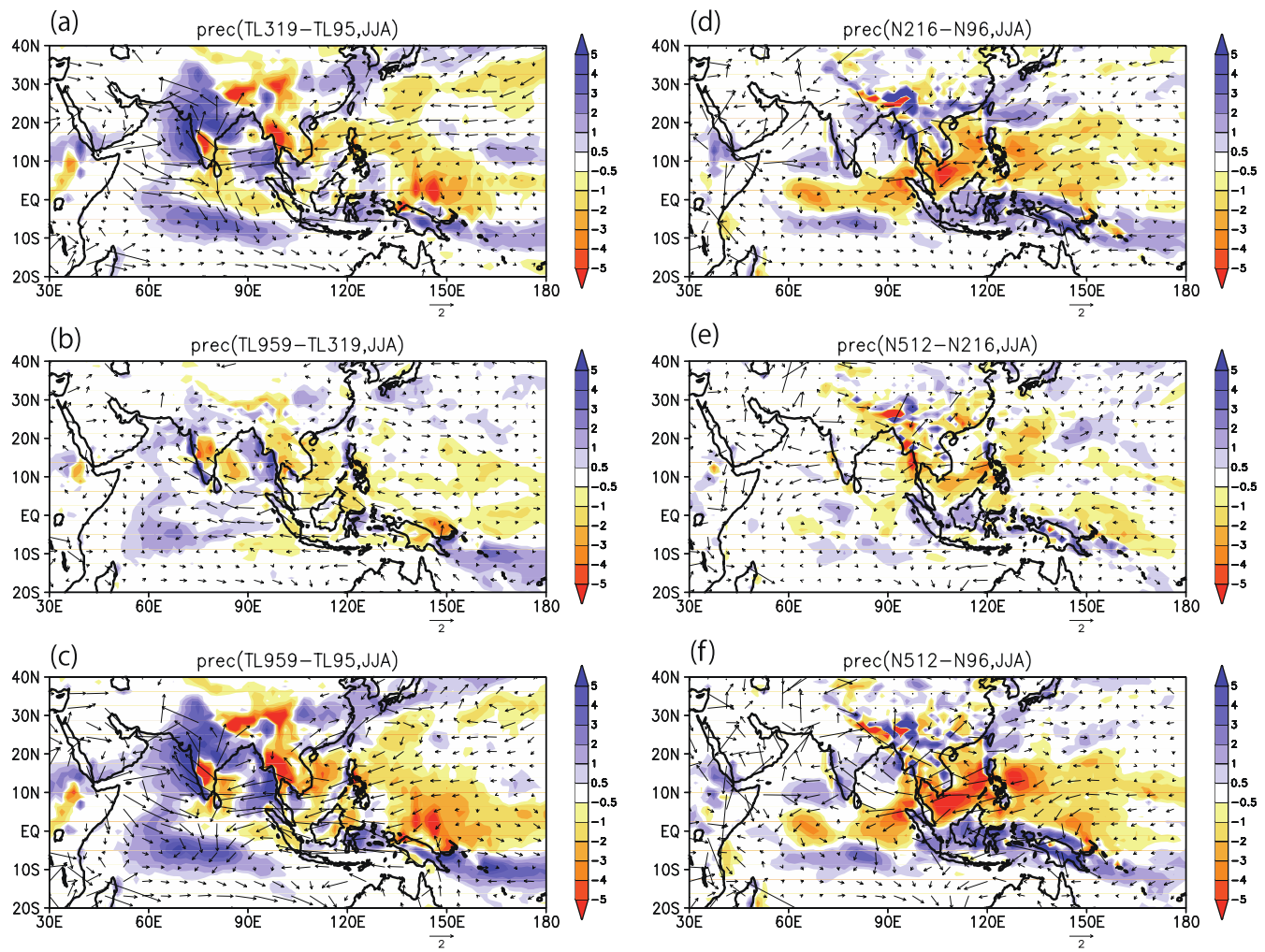

11 Figure 2: Resolution sensitivity of JJA precipitation (shaded, units: $\mathrm{mm}^{\mathrm{day}}{ }^{-1}$ ) and

12 horizontal $850 \mathrm{hPa}$ wind (vector, units: $\mathrm{m} \mathrm{s}^{-1}$ ) : (a) TL319-TL95, (b) TL959-TL319, and

13 (d) TL959-TL95 MRI-AGCM. Right panels are same as (a)-(c) but for (d) N216-N96,

14 (e) N512-N216, and (f) N512-N96 MetUM.

15 
(a)

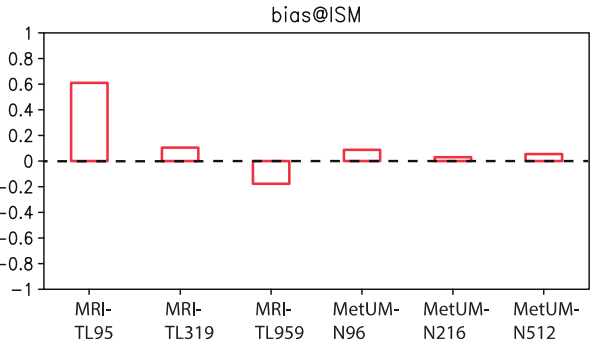

(b)

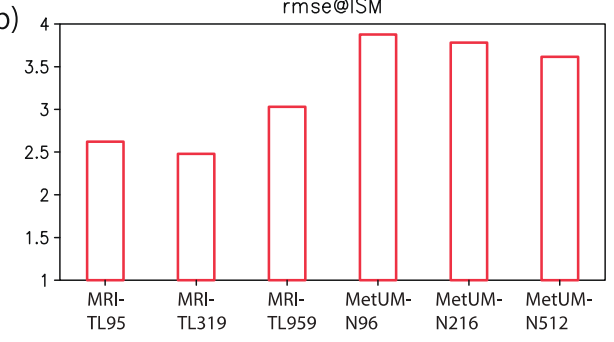

(c)

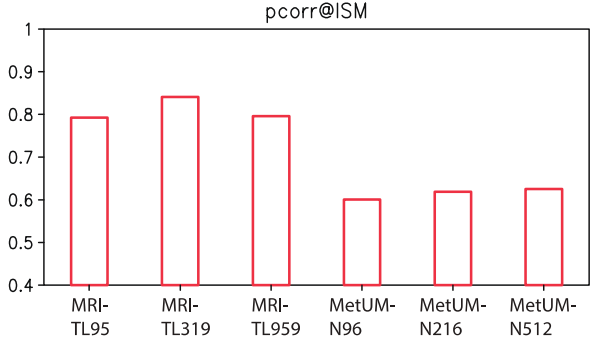

(d)

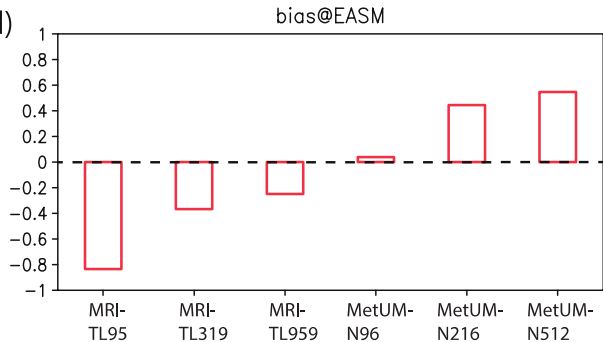

(e)

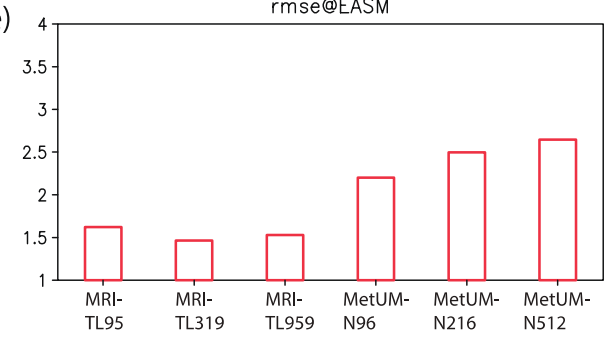

(f)

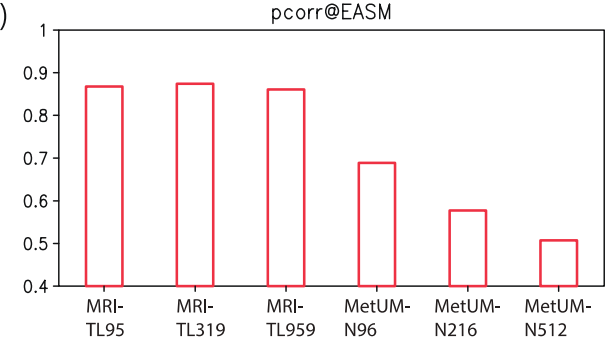

18 Figure 3: Area average over the tropical Indian Ocean $\left(20^{\circ} \mathrm{S}-20^{\circ} \mathrm{N}, 40-100^{\circ} \mathrm{E}\right)$ of (a)

19 mean JJA precipitation bias (units: $\mathrm{mm} \mathrm{day}^{-1}$ ), (b) RMSE, and (c) pattern correlation.

21 are re-gridded to CMAP resolution (2.5 degree). In (c) and (f), $\mathrm{p}$-value at $\mathrm{R}=0.4$ is $\mathrm{p}<$ 
(a)

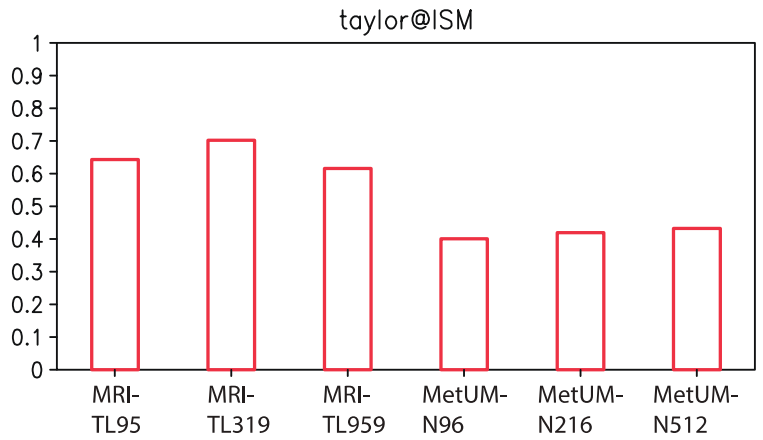

(b)

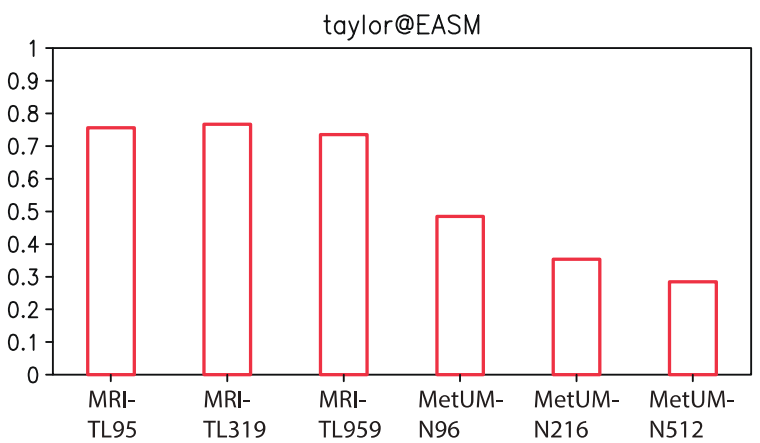

25

taylor@BAIU

(c)

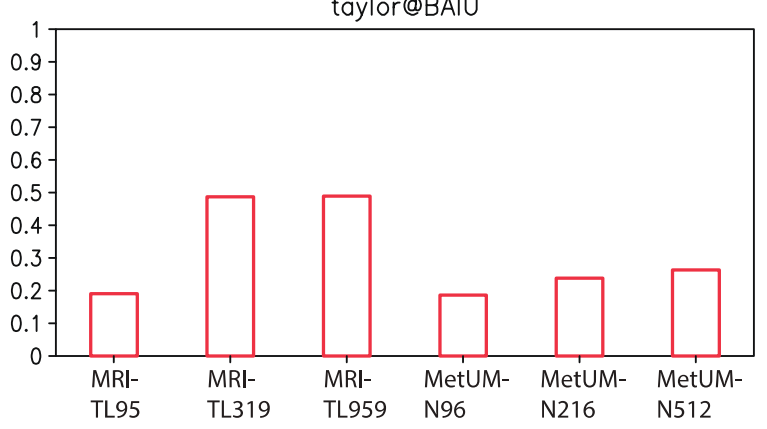

26 Figure 4: Taylor's skill scores (Taylor 2001) of JJA precipitation over (a) the tropical

27 Indian Ocean $\left(20^{\circ} \mathrm{S}-20^{\circ} \mathrm{N}, 40-100^{\circ} \mathrm{E}\right)$, and (b) the western Pacific $\left(0-40^{\circ} \mathrm{N}, 120-180^{\circ} \mathrm{E}\right)$,

28 and (c) Baiu-Meiyu front $\left(20-40^{\circ} \mathrm{N}, 120-150^{\circ} \mathrm{E}\right)$. All datasets are re-gridded to CMAP

29 resolution (2.5 degree).

30

31 

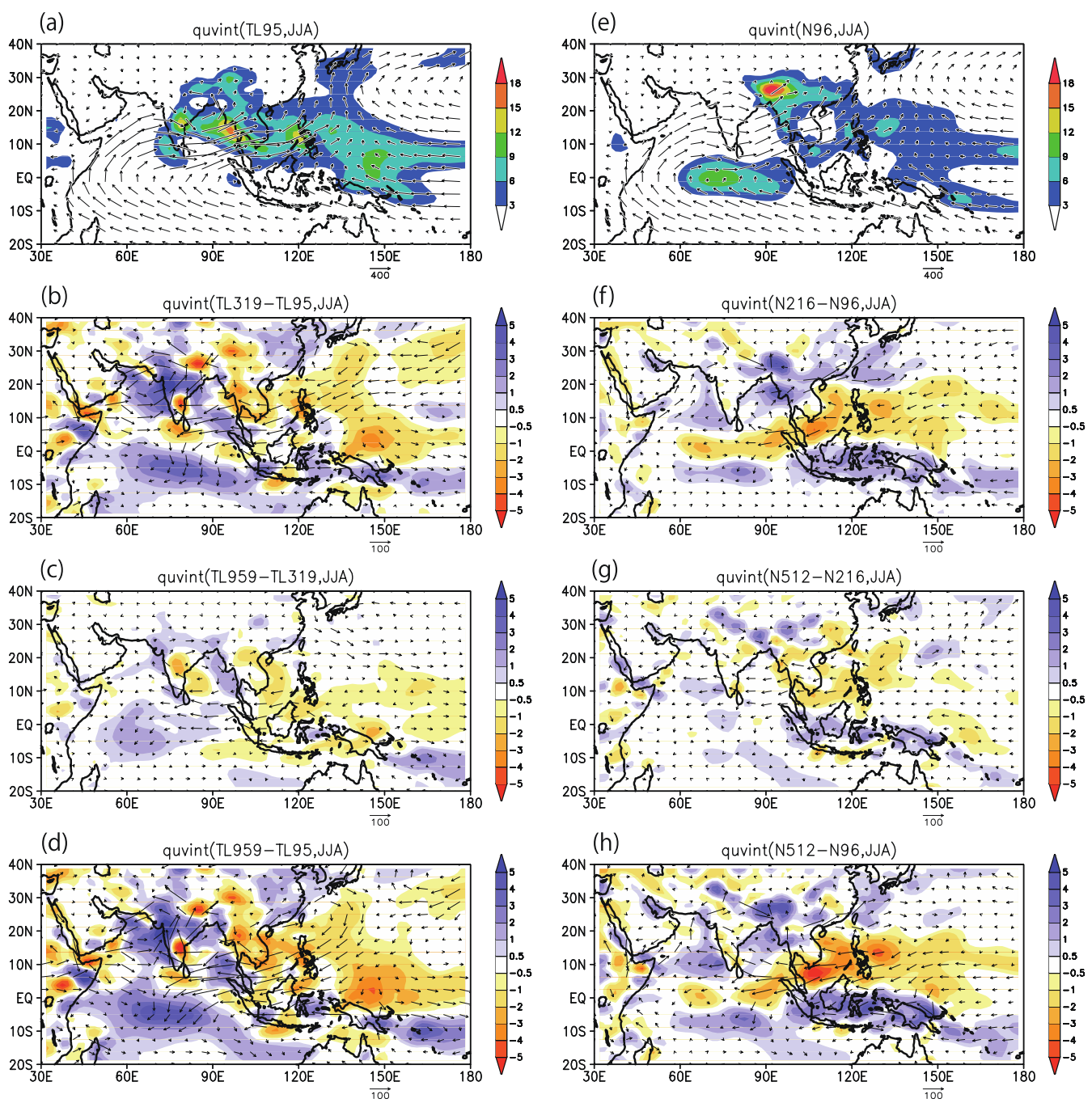

33 Figure 5: JJA vertical-integrated moisture flux (vector, units: $\mathrm{kg} \mathrm{m}^{-1} \mathrm{~s}^{-1}$ ) and its

34 convergence (shaded, units: mm day $^{-1}$ ) in (a) TL95 MRI-AGCM, (b) TL319-TL95, (c)

35 TL959-TL319, and (d) TL959-TL95. (e)-(h) are same as (a)-(d) but for (e) N96 MetUM,

36 (f) N216-N96, (g) N512-N216, and (d) N512-N96.

37 
(a)

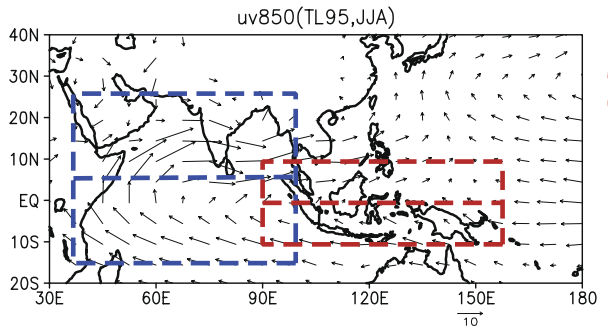

(b)

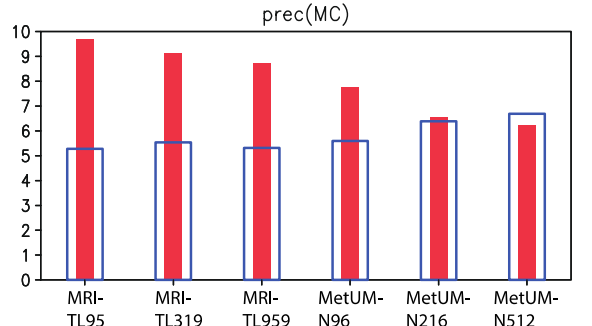

(c)

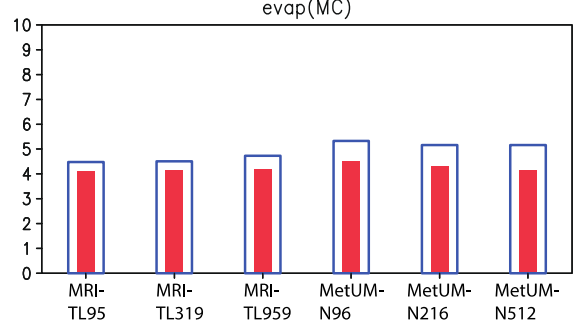

(d)

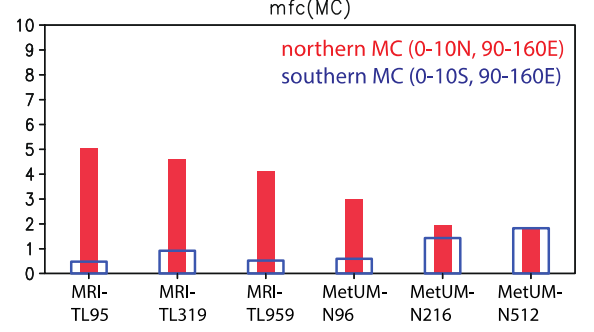

Indian Ocean (IO)

Maritime Continent

(MC) (e)

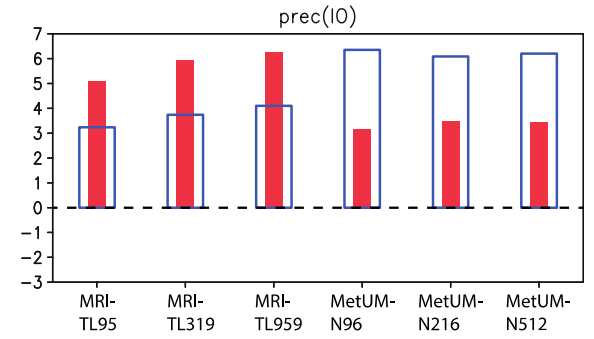

(f)

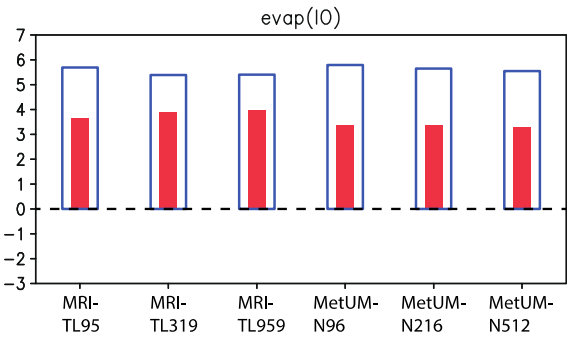

(g)

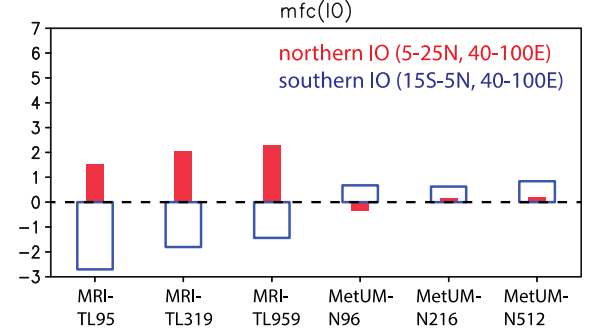

Figure 6: Resolution sensitivity of the JJA moisture budget over the regions outlined in (a) (units: $\mathrm{mm} \mathrm{day}{ }^{-1}$ ): (b) precipitation, (c) surface evaporation, and (d) moisture flux convergence. Red and blue bars correspond to the northern $\left(0-10^{\circ} \mathrm{N}, 90-160^{\circ} \mathrm{E}\right)$ and southern $\left(0-10^{\circ} \mathrm{S}, 90-160^{\circ} \mathrm{E}\right) \mathrm{MC}$ box regions, respectively. (e)-(g) are same as (b)-(d) for the Indian Ocean (IO) box region. Red and blue bars correspond to the northern $\left(5-25^{\circ} \mathrm{N}, 40-100^{\circ} \mathrm{E}\right)$ and southern $\left(15^{\circ} \mathrm{S}-5^{\circ} \mathrm{N}, 40-100^{\circ} \mathrm{E}\right) \mathrm{IO}$ box regions, respectively. 
(a)
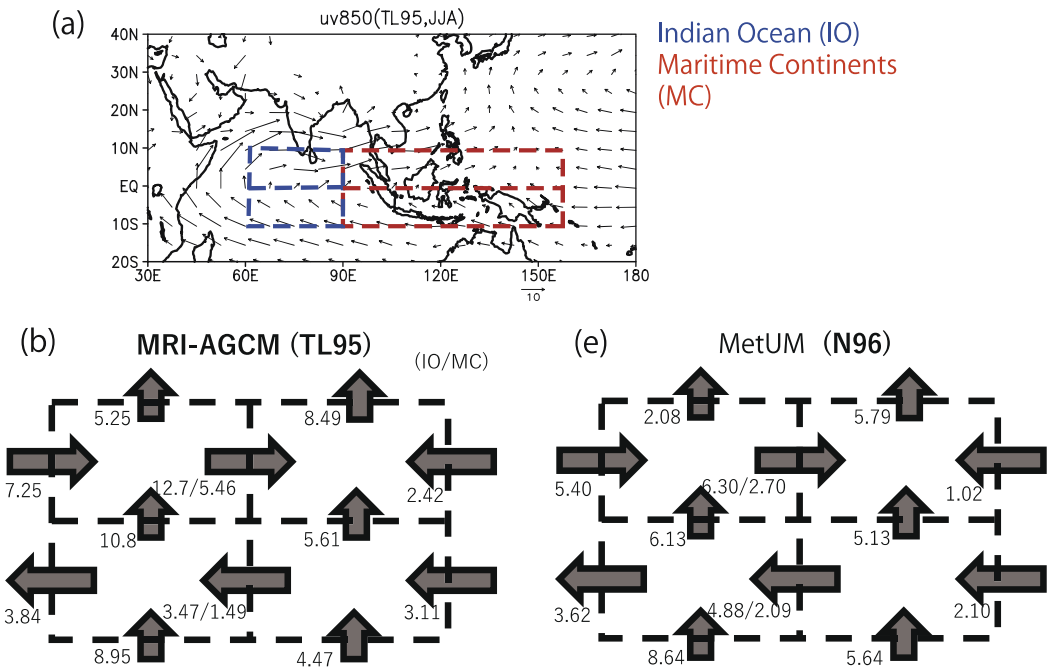

(c) MRI-AGCM (TL319-TL95)

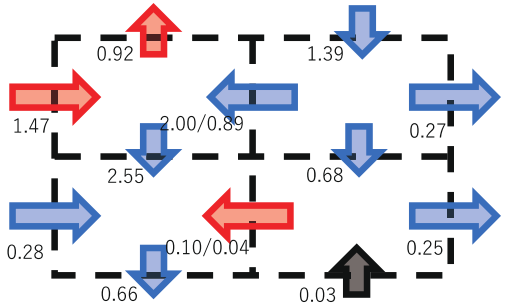

(f) MetUM (N216-N96)

(d) MRI-AGCM (TL959-TL95)
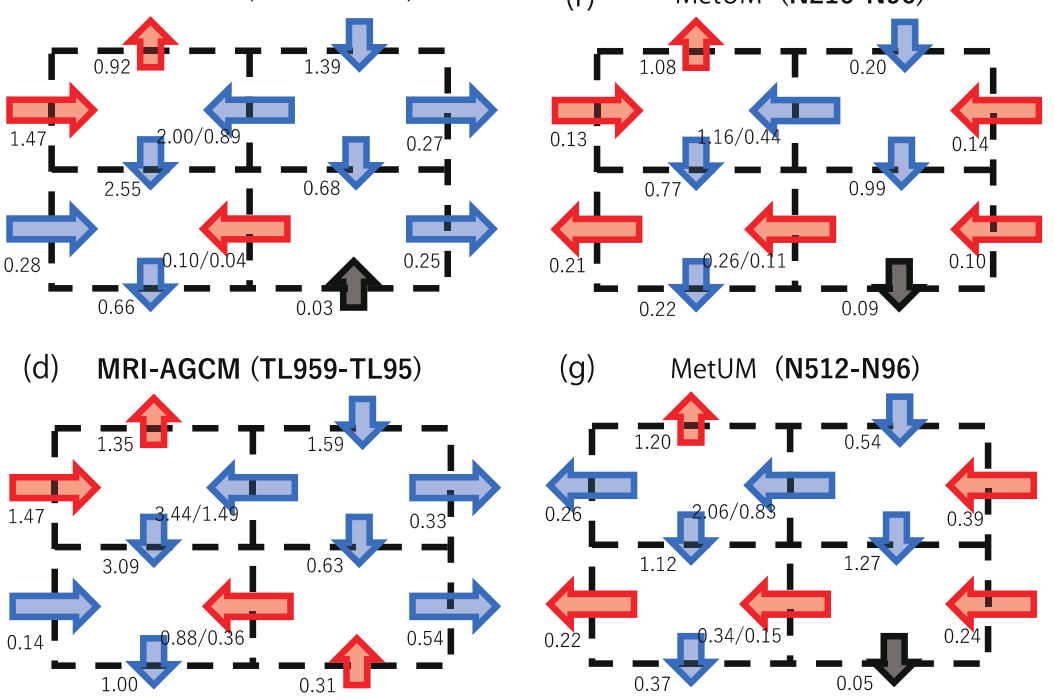

Figure 7: Resolution sensitivity of the JJA moisture flux across the borders shown in (a)

49 (units: $\mathrm{mm} \mathrm{day}^{-1}$ ). Since this is an area average quantity there are two values at the

50 borders between the Indian Ocean regions and Maritime Continent regions.: (b) TL95,

51 (c) TL319-TL95, and (d) TL959-TL95 MRI-AGCM. (e) N96, (f) N216-N96, and (g)

52 N512-N96 MetUM. Red (blue) arrows shows increase (decrease) of moisture flux. 
(a)

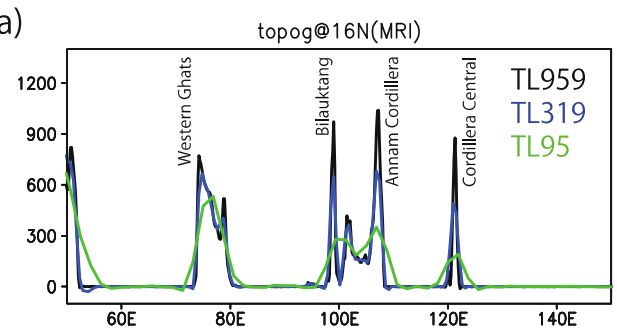

(b)

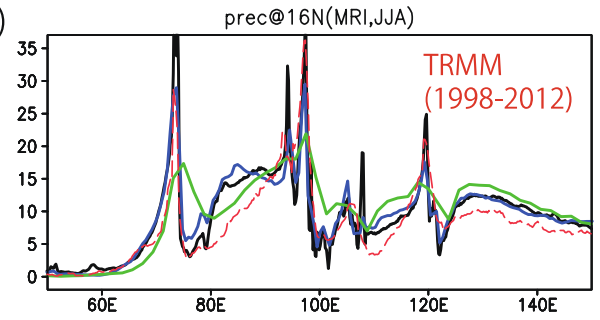

(c)

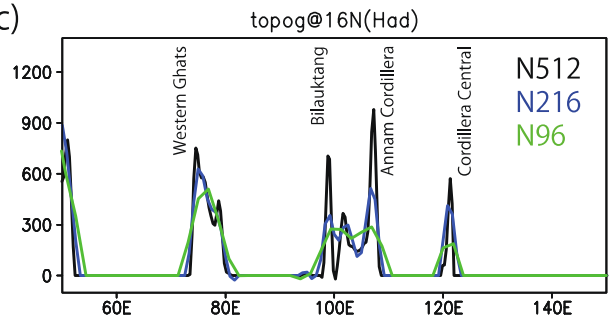

(d)

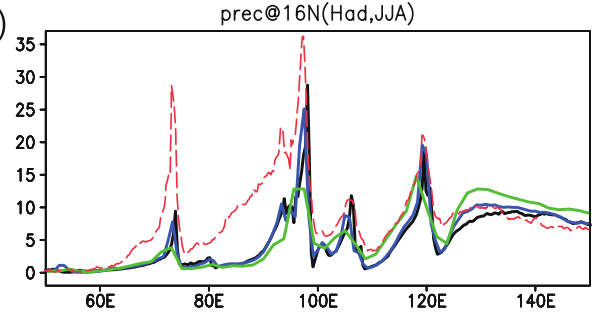

55 Figure 8: Zonal section at $16^{\circ} \mathrm{N}$ showing the resolution sensitivity of topography (units:

m) in MRI-AGCM (a) and MetUM (c), and JJA precipitation (units: $\mathrm{mm}$ day $^{-1}$ ) in

57 MRI-AGCM (b) and $\operatorname{MetUM~(d).~}$

58

59 
(a)

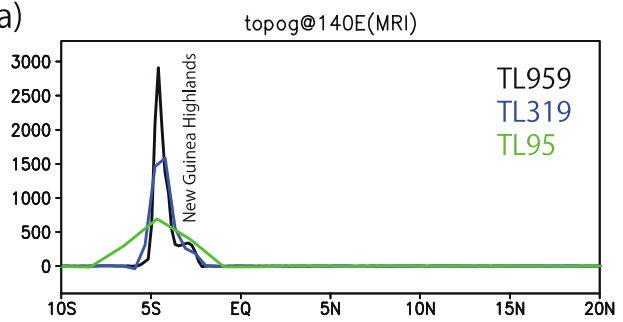

(b)

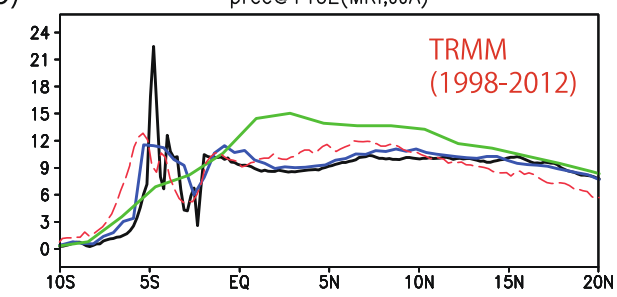

(c)

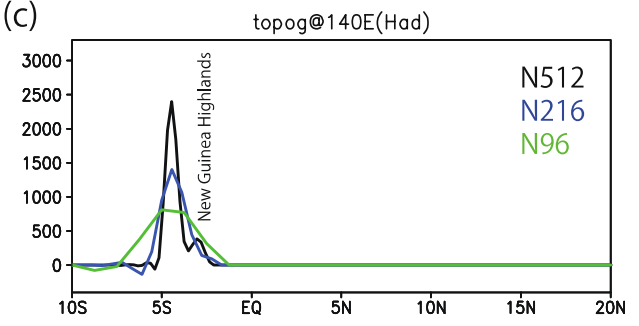

(d)

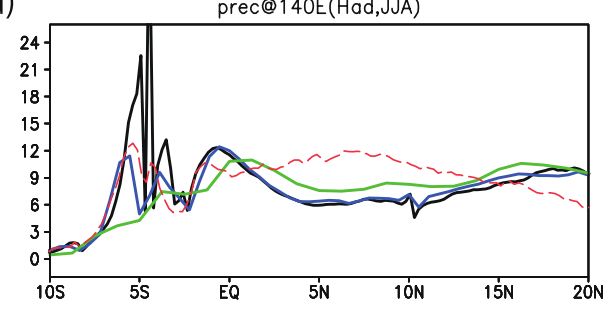

61 Figure 9: Same as Fig. 8, for a meridional section at $140^{\circ} \mathrm{E}$.

62

63 
(a)

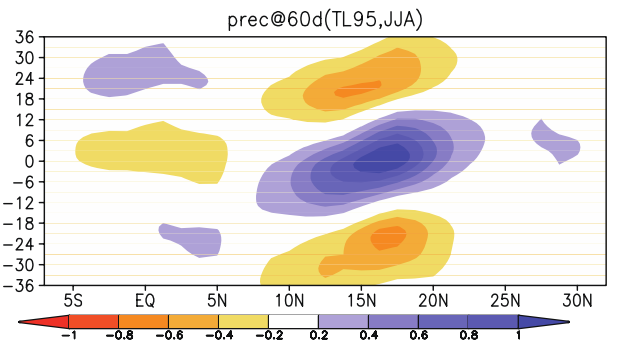

(b)

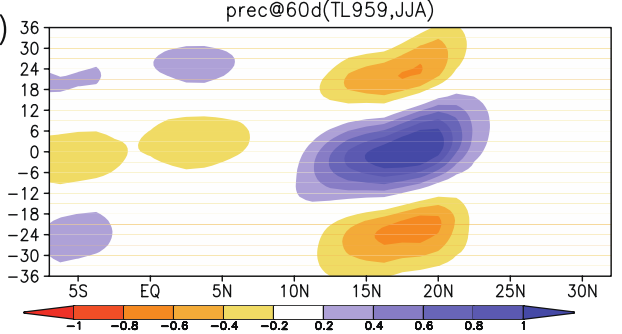

(c)

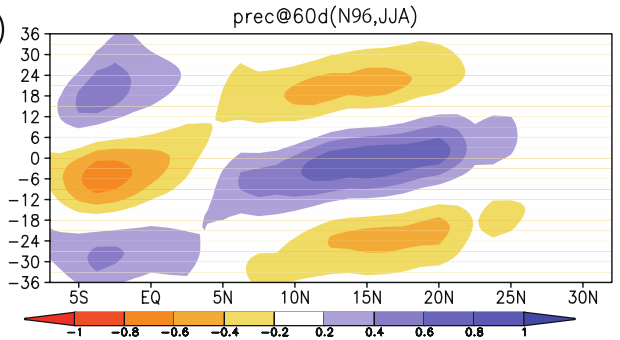

(d)

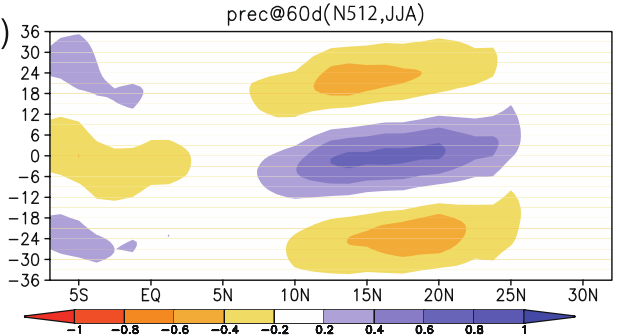

65 Figure 10: Latitude-time sections of lag covariance of intra-seasonal rainfall variability

66 onto BSISO index (21-61 day rainfall variability over $12-22^{\circ} \mathrm{N}, 70-95^{\circ} \mathrm{E}$ during

67 June-August) in (a) TL95 MRI-AGCM3, (b) TL959 MRI-AGCM3, (c) N96 MetUM,

68 and (d) N512 MetUM. Units are mm day ${ }^{-1}$. The covariance fields were normalized by

69 the standard deviation of BSISO index.

70

71 
(a)

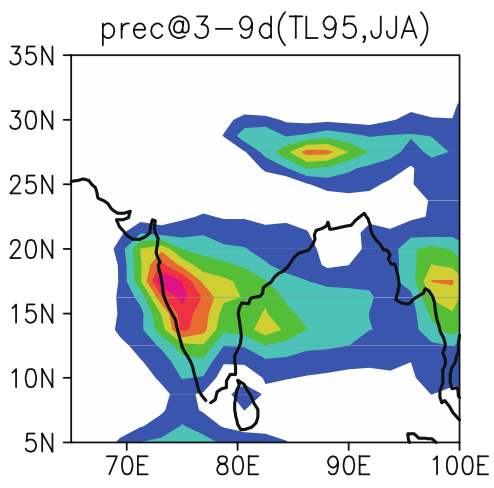

(b)

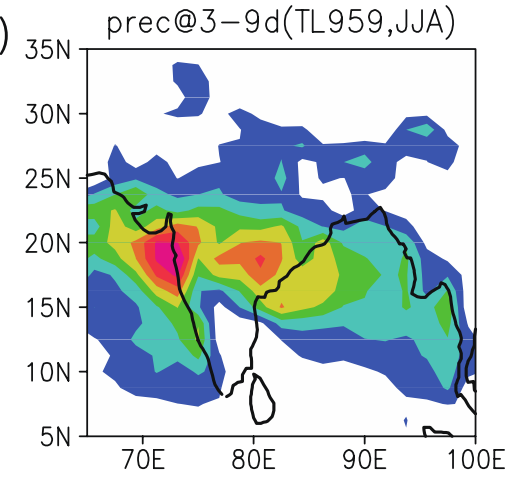

72

(c) $35 \mathrm{prec} @ 3-9 \mathrm{~d}$ (TL959-TL95,JJA)

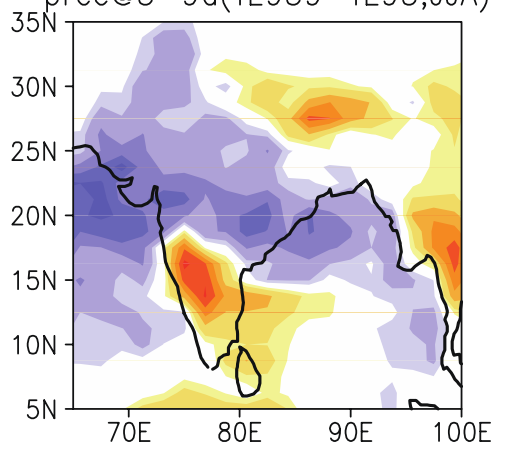

(d)

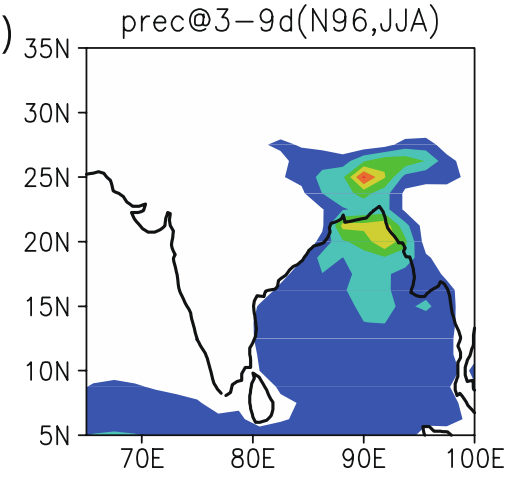

(e)

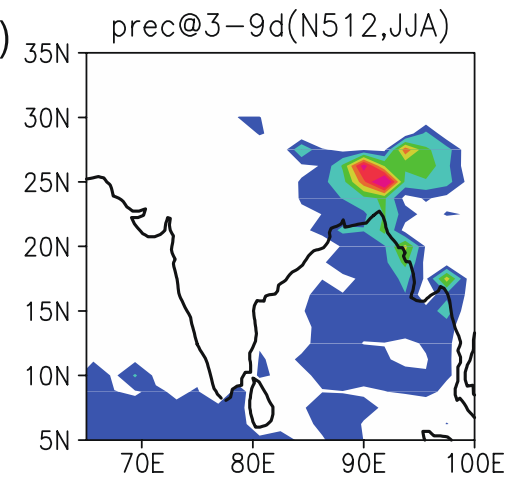

(f)

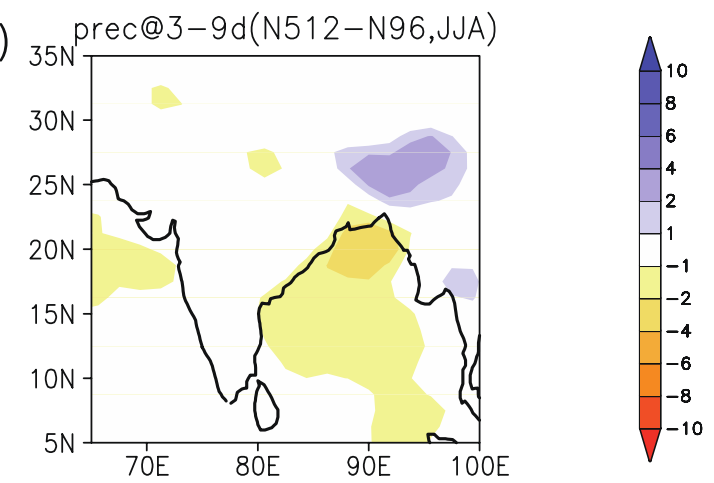

73 Figure 11: (a) Standard deviation of synoptic-scale (3-9 day band-passed) rainfall

74 variability during JJA (shaded, units: $\mathrm{mm} \mathrm{day}^{-1}$ ) in (a) TL95, (b) TL959, and (c) its

75 difference (TL959-TL95). (d)-(f) is same as (a)-(c) but for MetUM: (d) N96, (e) N512,

76 and (f) its difference (N512-N96). 
(a)

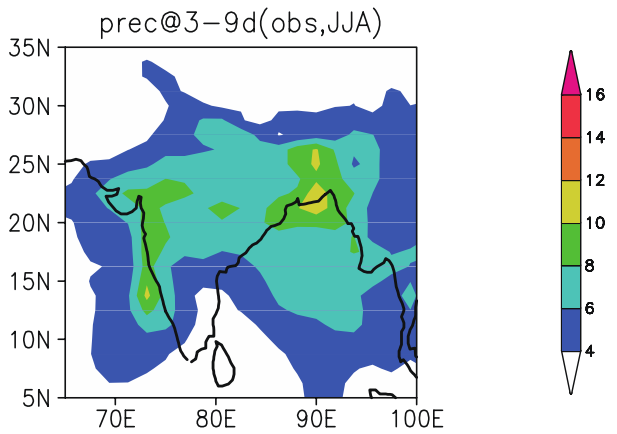

(b) $35 \mathrm{~N}$ prec@3-9d(TL95-obs, JJA)
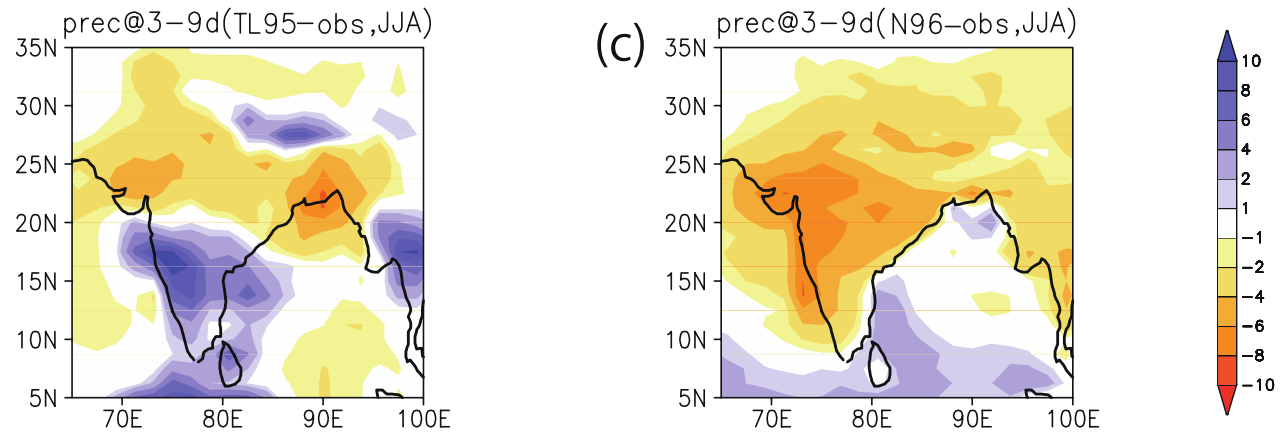

79 Figure 12: Same as Fig. 11 but for (a) GPCP daily observation (1997-2012), (b) TL95

80 MRI-AGCM minus GPCP, and (c) N96 MetUM minus GPCP.

81

82 

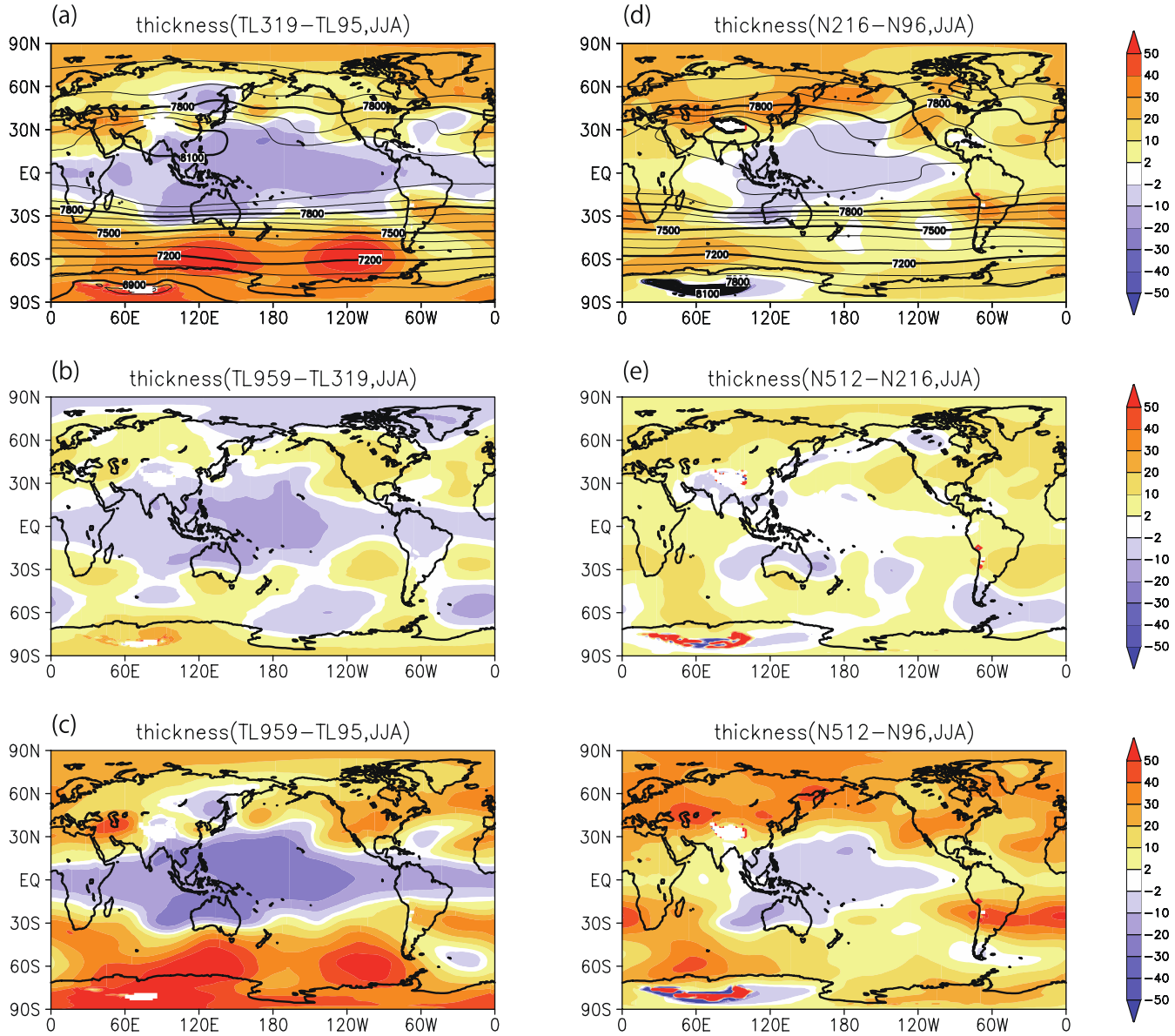

84 Figure 13: Differences in JJA 200-600 hPa upper tropospheric thickness (shaded, units:

m): (a) TL319-TL95, (b) TL959-TL319, and (c) TL959-TL95 in MRI-AGCM. (d)-(f) are same as (a)-(c) but for (d) N216-N96, (e) N512-N216, and (f) N512-N96 in MetUM.

87 Contours in (a) show upper tropospheric thickness in TL95 MRI-AGCM (units: m), and 88 contours in (d) are for N96 MetUM. 
(a)

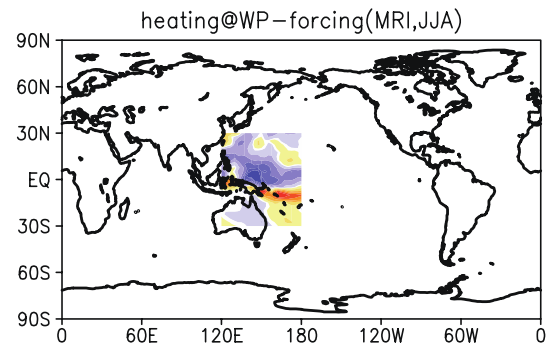

(b)

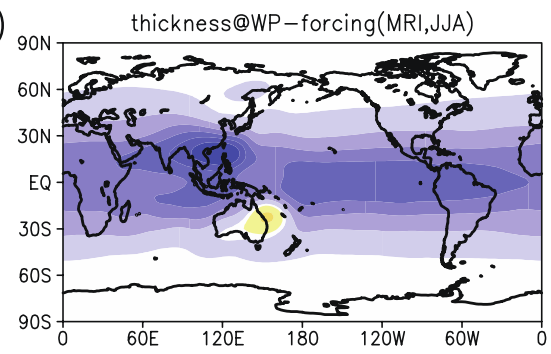

(c)

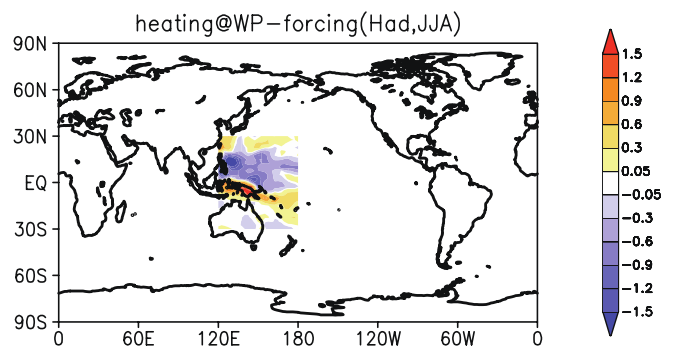

(d)

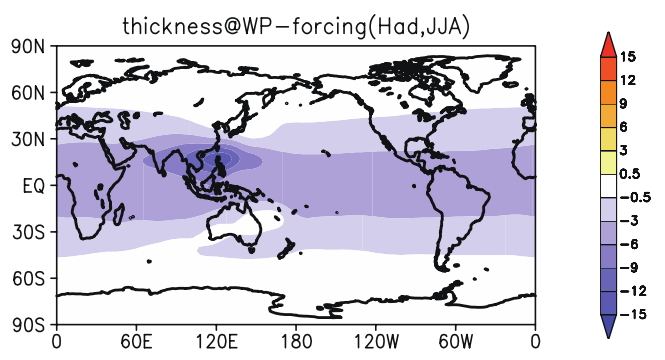

92 Figure 14: Responses (200-600 hPa thickness) to individual heating in MRI-AGCM and

93 MetUM in a linear model. (a) Heating distribution (100-1000 hPa averaged, units: $\mathrm{K}$

$\left.94 \mathrm{day}^{-1}\right)$ of western Pacific forcing $\left(30^{\circ} \mathrm{S}-30^{\circ} \mathrm{N}, 120-180^{\circ} \mathrm{E}\right)$ and (b) response to the

95 forcing (units: m) in MRI-AGCM. (c)-(d) are same as (a)-(b) but for MetUM.

96

97 


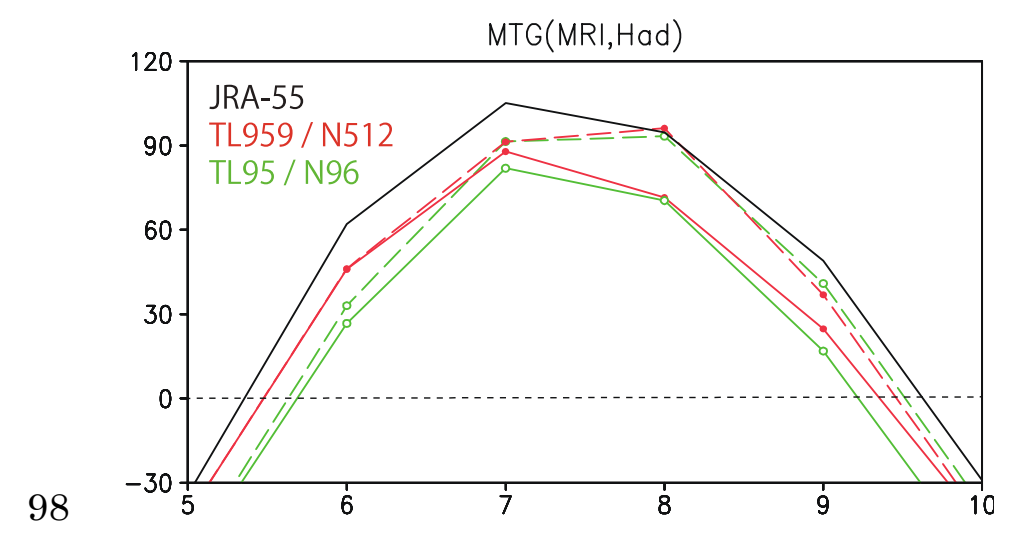

99 Figure 15: Seasonal evolution of monsoon temperature gradient (MTG, units: $\mathrm{m}$ ) in

100 Reanalysis (JRA-55, black solid line), MRI-AGCM (solid coloured lines) and MetUM

101 (dash coloured lines). Higher resolution models are shown in red and lower resolution

102 GCMs are shown in green.

103

104 
(a) TL95/N96 $\operatorname{prec}($ MRI-Had,JJA)

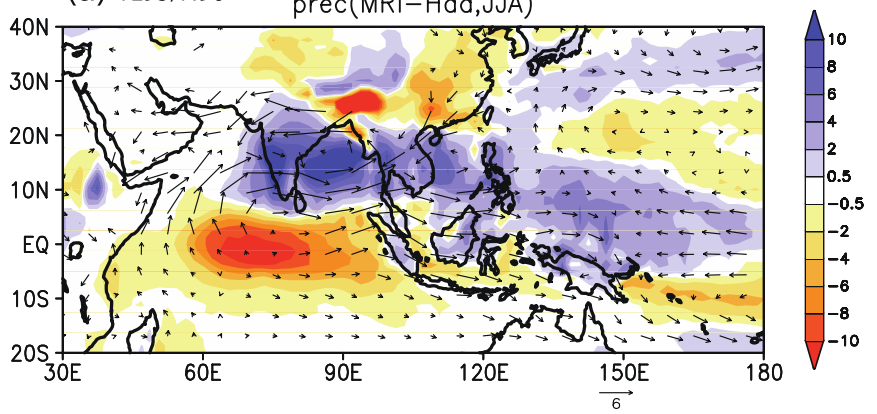

(b) TL319/N216

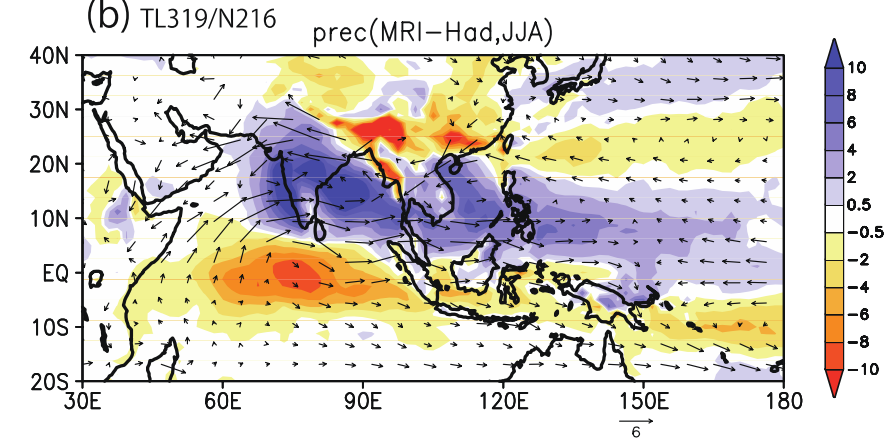

(C) TL959/N512 $\operatorname{prec}(\mathrm{MRI}-\mathrm{Had}, \mathrm{JJA})$

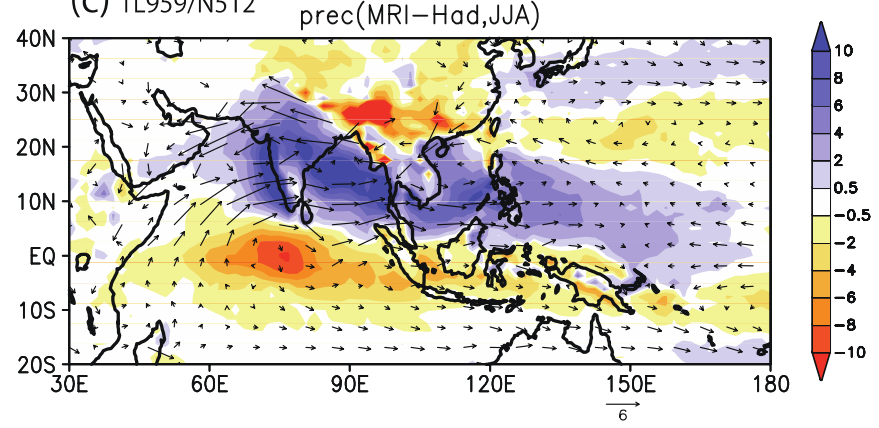

106 Figure 16: Difference in JJA precipitation (shaded, units: $\mathrm{mm} \mathrm{day}^{-1}$ ) and horizontal 850

$107 \mathrm{hPa}$ wind (vector, units: $\mathrm{m} \mathrm{s}^{-1}$ ) between the two GCMs compared in this study: (a)TL95

108 MRI-AGCM minus N96 MetUM, (b) TL319 MRI-AGCM minus N216 MetUM, and (c)

109 TL959 MRI-AGCM minus N512 MetUM. 